\title{
The long adventurous journey of rhombic lip cells in jawed vertebrates: a comparative developmental analysis
}

\author{
Mario F. Wullimann ${ }^{1 *}$, Thomas Mueller ${ }^{2}$, Martin Distel ${ }^{3 \dagger}$, Andreas Babaryka ${ }^{3}$, Benedikt Grothe ${ }^{1}$ and \\ Reinhard W. Köster ${ }^{3+}$ \\ Graduate School of Systemic Neurosciences and Department Biology II, Ludwig-Maximilians-Universität Munich, Planegg, Germany \\ 2 Department Developmental Biology, Institute of Biology I, University of Freiburg, Freiburg, Germany \\ 3 Institute of Developmental Genetics, Helmholtz Zentrum München, German Research Center for Environmental Health, Neuherberg, Germany
}

\section{Edited by:}

Agustín González, Universidad Complutense de Madrid, Spain

Reviewed by:

Susan Dymecki, Harvard University, USA

Rob Machold, New York University School of Medicine, USA

Pilar Aroca, University of Murcia, Spain

\section{*Correspondence:}

Mario F. Wullimann, Graduate School of Systemic Neurosciences and Division of Neurobiology, Department Biology II, Ludwig-Maximilians-Universität Munich, Grosshadernerstr. 2, D-82152

Planegg, Bavaria, Germany.

e-mail:wullimann@bio.Imu.de

\section{${ }^{+}$Current address:}

Martin Distel, Department of Cellular and Molecular Medicine, University of California San Diego, 9500 Gilman

Drive, La Jolla, CA 92093-0380, USA;

Reinhard W. Köster, Cell Biology and Cell Physiology, Institute of Zoology, Technische Universität Braunschweig, Spielmannstr. 7, D-38106

Braunschweig, Germany.
This review summarizes vertebrate rhombic lip and early cerebellar development covering classic approaches up to modern developmental genetics which identifies the relevant differential gene expression domains and their progeny. Most of this information is derived from amniotes. However, progress in anamniotes, particularly in the zebrafish, has recently been made. The current picture suggests that rhombic lip and cerebellar development in jawed vertebrates (gnathostomes) share many characteristics. Regarding cerebellar development, these include a ptf1a expressing ventral cerebellar proliferation (VCP) giving rise to Purkinje cells and other inhibitory cerebellar cell types, and an atoh 1 expressing upper rhombic lip giving rise to an external granular layer (EGL, i.e., excitatory granule cells) and an early ventral migration into the anterior rhombencephalon (cholinergic nuclei). As for the lower rhombic lip (LRL), gnathostome commonalities likely include the formation of precerebellar nuclei (mossy fiber origins) and partially primary auditory nuclei (likely convergently evolved) from the atoh 1 expressing dorsal zone. The fate of the ptf1a expressing ventral LRL zone which gives rise to (excitatory cells of) the inferior olive (climbing fiber origin) and (inhibitory cells of ) cochlear nuclei in amniotes, has not been determined in anamniotes. Special for the zebrafish in comparison to amniotes is the predominant origin of anamniote excitatory deep cerebellar nuclei homologs (i.e., eurydendroid cells) from ptf1a expressing VCP cells, the sequential activity of various atoh1 paralogs and the incomplete coverage of the subpial cerebellar plate with proliferative EGL cells. Nevertheless, the conclusion that a rhombic lip and its major derivatives evolved with gnathostome vertebrates only and are thus not an ancestral craniate character complex is supported by the absence of a cerebellum (and likely absence of its afferent and efferent nuclei) in jawless fishes

Keywords: atoh1, cerebellum, cochlear nuclei, precerebellar systems, ptf1a, wnt1, zebrafish, rhombic lip

\section{AMNIOTE RHOMBIC LIP AND CEREBELLAR DEVELOPMENT GENERAL}

The vertebrate hindbrain (rhombencephalon) consists of an anterior metencephalon (rhombomere 1), including the cerebellum and pons, and a posterior myelencephalon (remaining rhombomeres). The embryonic anterior rhombencephalon has a dorsal rhombic groove (rhombic fossa) because the dorsal part of the neural tube wall, the alar plates, are laterally extended and form a V-shaped medulla oblongata in transverse section (Figures 1A,B). In contrast, the alar plates of the posterior rhombencephalon and the spinal cord approach each other closely in the dorsal midline and are kept together by a thin roof plate, reminiscent of a closed embryonic neural tube (Figure 1C). However, the alar plates of the anterior rhombencephalon are also interconnected by the roof plate which is greatly mediolaterally extended (Figure 1B). This epithelial tela covers the rhombic fossa and will generate (together with mesodermal vascular tissue at its peripheral side) a convoluted chorioideal plexus that is involved in cerebrospinal fluid production (Redzic et al., 2005). Interestingly, the secreted factor Sonic Hedgehog plays a specific signaling role for both the proliferation of the neuroectodermal tela itself - by acting on its germinative domain at its lateral point of attachment at the alar plate - as well as for the mesodermal vascularization of the developing choroid plexus (Huang et al., 2009; Nielsen and Dymecki, 2010). During embryonic development, the laterally displaced alar plate edges in amniotes constitute the rhombic lip which have long been known to be highly proliferative and to give rise to various brain structures that are finally located remote from their rhombic lip origin. Here, we will first review major steps in the understanding of amniote rhombic lip (including cerebellar) development before discussing related progress in anamniotes, particularly in zebrafish. With regard to amniotes, the organization of the review aims to give a sketch of how the field progressed historically ("Lower rhombic lip," "Cerebellum/Upper rhombic lip") before going into modern molecular data in amniotes ("Molecular revolutions").

\section{LOWER RHOMBIC LIP}

Both proliferation in the rhombic lip (Rautenlippe) and cellular migration into the pontine and inferior olivary regions are visible in normal histological material and were first described beginning in the late nineteenth century by Wilhelm His followed by various contemporaries (see Nieuwenhuys, 1998 for a review) who 


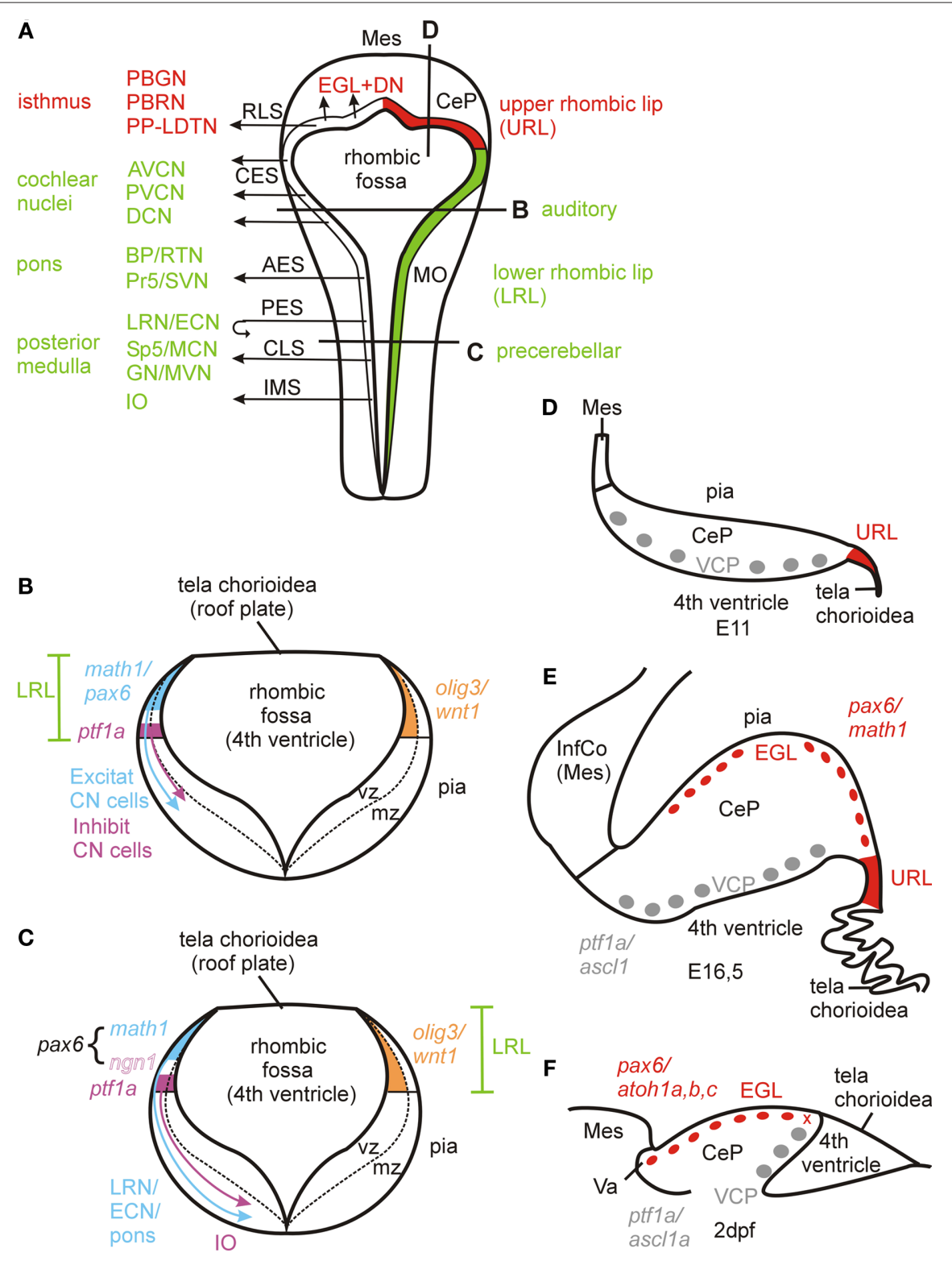

FIGURE 1 | (A-E) Amniote rhombic lip development. (A) Dorsal schematic view of embryonic amniote rhombencephalon showing rhombic lip and its derivatives. Many of these facts were first revealed by pre-genetic studies (see text for older citations) and later confirmed and detailed by molecular and genetic approaches. Anterior origin of primary auditory nuclei is indicated for mammals, in birds they originate along the entire lower rhombic lip (see text). (B-C) Schematic transverse section trough lower rhombic lip at two levels showing critical differential gene expression patterns. Compiled from Hoshino et al. (2005), Machold and Fishell (2005), Wang et al. (2005), Landsberg et al. (2005), Farago et al. (2006), Machold et al. (2007), Liu et al. (2008), Rose et al. (2009), Fujiyama et al. (2009), and Storm et al. (2009). Note that the Imx1a/wnt1 positive generative zone for the choroid plexus in the most dorsal lower rhombic lip (Landsberg et al., 2005; Huang et al., 2009; Nielsen and Dymecki, 2010) is not shown. See text for some additional math1 dependent medullary nuclei as shown in Rose et al. (2009). (D-E) Schematic view of sagittal sections of mouse cerebellum at E11 when EGL has not yet formed (after photo in Goldowitz and Hamre, 1998) and E16.5 when EGL has formed (after photo in Sillitoe and Joyner, 2007). Note that this difference between an anterior ventricular proliferative zone and URL emerges around E10 (DN cells formation) and that classical descriptions of the earlier upper rhombic lip include both (see text). (F) Sagittal section of zebrafish cerebellar plate at $2 \mathrm{dpf}$ (redrawn after Kani et al., 2010). The $x$ symbol indicates the hypothetical site of the ventricular origin of subpial atoh 1 positive cells and, thus, the structure corresponding to the amniote URL (see text). AES, anterior extramural stream; AVCN, anteroventral cochlear nucleus; $\mathrm{BP}$, basal pons; CeP, cerebellar plate; $\mathrm{CES}$, cochlear extramural stream; CLS, caudal rhombic lip stream (of Rose et al., 2009); CN, cochlear nucleus; DCN, dorsal cochlear nucleus; DN, deep cerebellar nuclei; ECN, external cuneate nucleus; EGL, external granular (or germinative) layer; GN, gracile nucleus; IMS, intramural stream; InfCo, inferior colliculus; IO, inferior olive; LRL, lower rhombic lip; LRN, lateral reticular nucleus; $M C N$, medial cuneate nucleus; Mes, mesencephalon; $\mathrm{MO}$, medulla oblongata; MVN, medial vestibular nucleus; PBGN, parabigeminal nucleus; PBRN, parabrachial nucleus; PES, posterior extramural stream; PP-LDTN, pedunculopontine-laterodorsal tegmental nuclei; Pr5, principal sensory trigeminal nucleus; PVCN, posteroventral cochlear nucleus; RLS, rostral rhombic lip stream; RTN, reticulotegmental pontine nucleus; Sp5, spinal trigeminal nucleus; SVN, superior vestibular nucleus; URL, upper rhombic lip; VCP, ventral cerebellar proliferation (ventricular germinal matrix). 
reported the situation for the human embryo. Later, Harkmark (1954) reported rhombic lip derived migration into inferior olive and pons in the chicken embryo describing how mitotic activity in the rhombic lip is followed by the appearance of ventrally directed streams of increasingly differentiating cells into inferior olive and pons. He additionally performed lesion experiments which while not directly demonstrating the fate of lesioned rhombic lip cells - allowed a first hypothesis on the spatiotemporal origin of migrating rhombic lip cells. An important step forward in this field emerged with autoradiography (Taber-Pierce, 1966; Altman and Bayer, 1987a,b,c,d). These studies applied tritiated thymidine to embryonic rodents and used short and long term survival times to infer birth dates, migration routes and final destination of rhombic lip derived cells within the ventral medulla oblongata (Figure 1). During embryonic days 13-19, the rhombic lip of the rat brain produces - in the following order-neurons destined for the inferior olive (intramural stream, IMS), the lateral reticular and external cuneate nuclei (posterior extramural stream), the pontine reticulotegmental nucleus and the basal pontine gray (anterior extramural stream). The posterior extramural stream crosses the midline floor plate and, thus, the lateral reticular and external cuneate cells become to lie on the contralateral side. All these structures are called precerebellar, since they provide axonal input to the cerebellum (mossy fibers to granule cells, except for inferior olive: climbing fibers to Purkinje cells). Most of these afferent cerebellar projections occur in a contralateral manner. Even the adult ipsilaterally projecting lateral reticular and external cuneate nuclei have a developmental origin in the contralateral rhombic lip. Horseradish peroxidase injections at various relevant developmental time points confirmed that intramural (submarginal) and extramural (marginal) streams contribute inferior olivary and lateral reticular/external cuneate neurons, respectively (Bourrat and Sotelo, 1988, 1990). The latter studies in the embryonic rat brain also showed how leading neurites pioneer the migration path of lateral reticular/external cuneate and inferior olivary neurons and provided many details of this neuronal maturation. Similar migration events of precerebellar rhombic lip neurons were also described in the mouse by SEM/TEM studies (Ono and Kawamura, 1989, 1990) and in the chick by transfecting rhombic lip cells with enhanced green fluorescent protein (EGFP) expression vectors by electroporation (Ono et al., 2004). Also, the chick-quail transplantation system was used to show inferior olive/ pons origins in rhombic lip (Tan and LeDouarin, 1991). Diffusible molecules (such as Netrin 1 and Slit1/2 in the floor plate) and their receptors (Netrin1 receptors DCC and Unc5, Slit receptor Robo2), as well as Ephrins and Eph receptors are involved in neurite guided migration (incl. its termination) of precerebellar neuronal somata in a complex manner. After settlement of these neurons, these factors also regulate topographically ordered axonal pathfinding toward their cerebellar projection targets (Chédotal et al., 1997; Bloch-Gallego et al., 1999; Wingate, 2001; Sotelo, 2004).

All of these studies document rare cases of central nervous system tangential migration of neural cells, which runs perpendicular to conventional radial migration (during the latter, cells move along radial glia fibers from ventricle toward pia). Tangential migrations also exist in other parts of the brain, for example the tangentially moving cell streams from the medial ganglionic eminence into the cortex or the dorsoventral neuronal migration in the spinal cord. Thus, rhombic lip derived migration involves a massive transgression of longitudinal zones, because these migrating alar plate cells eventually end up in the basal plate (inferior olive, pons, lateral reticular nucleus) or migrate at least through it before ending in the alar plate of the other brain side (external cuneate nucleus).

Much later - probably because of their less spectacular, shorterdistance migration - all three (dorsal, anteroventral, posteroventral) mammalian cochlear nuclei (DCN, AVCN, PVCN) were also described to derive at least partially from the rhombic lip (autoradiography: Taber-Pierce, 1967, HRP-labeling: Willard and Martin, 1986; cerebellar mutant studies: Berrebi et al., 1990, BrDU/DiI labeling: Ivanova and Yuasa, 1998). Finally, genetic studies showed in more detail that the mammalian cochlear nuclei develop from a portion of the rhombic lip that lies anterior to the region of the rhombic lip which gives rise to the extra- and intramural stream for precerebellar nuclei. For example, a sophisticated approach of intersectional and subtractive genetic mapping of wingless homolog wnt1 (longitudinally expressed in the rhombic lip, see below) expressing cells in rhombomeres $3 / 5$ (where the zinc-finger transcription factor gene Krox20 is selectively expressed; Farago et al., 2006) or specific transgenic fate mapping of Math5 expressing cells (Atoh7; Saul et al., 2008) revealed cochlear derivatives in detail. A rhombic lip origin was also reported for the chick primary auditory nuclei (Golgi stains and DiI labeling; Book and Morest, 1990). Interestingly however, the origin of chick primary auditory nuclei is not restricted to the anterior rhombic lip as in mammals, but extends throughout the medulla oblongata (Marín and Puelles, 1995; Cambronero and Puelles, 2000). This is strong evidence for an independent origin of archosaur and mammalian hearing, which is in line with the fossil record indicating an independent evolution of tympanic ears (Clack, 1997) and with parallel evolution of neuronal mechanisms, for instance for sound localization (Grothe, 2003; Grothe et al., 2004).

In summary, the longitudinally running amniote rhombic lip that flanks the rhombic fossa laterally, the so-called caudal or lower rhombic lip (LRL) gives rise to cochlear nuclei anteriorly in mammals (but all along the rhombic lip in birds) and precerebellar nuclei more posteriorly (Figure 1).

\section{CEREBELLUM/UPPER RHOMBIC LIP}

At their anterior pole, the longitudinally running rhombic lips fuse by forming a transverse bridge which will give rise to the primordium of the cerebellum (cerebellar plate), the deep cerebellar nuclei $(\mathrm{DN})$, and the proliferative external granular layer (EGL, Figure 1A). To discriminate it from the caudal or lower rhombic lip, this anterior rhombic lip bridge has variedly been refered to as the rostral, cerebellar, or upper rhombic lip (URL). During embryonic development (around E10 in the mouse), it separates into two germinative zones: a fastly expanding anterior, ventricularly located ventral cerebellar proliferation (VCP, Figure 1D) and the so-called germinal trigone, which is the posterior rim of the initial cerebellar rhombic lip bridge (nicely depicted in Goldowitz and Hamre, 1998). While classical descriptions of the very early rhombic lip implicitly included both germinative zones, a consensus emerged meanwhile to refer only to the posterior proliferative zone (germinal trigone) as the URL and we follow this restricted definition of URL (Figure 1A). For our purpose here it is important 
to realize that both the VCP in the developing cerebellar plate and the URL are principally ventricularly located proliferative areas, unlike the later emerging and continued proliferative EGL which is subpially located.

In amniote cerebellar development, different classes of neuronal cells were described in classical histology to be generated in subsequent waves (for an excellent review see Sotelo, 2004; for adult cerebellar organization, see: Ito, 2006). In chick cerebellar development, the first wave of postmitotic neuronal cells destined to become the deep cerebellar nuclei (DN) originates at the ventricle of the early cerebellar plate, apparently in the VCP (work of Feirabend, discussed by Dubbeldam, 1998). After migrating somewhat toward the periphery, these future DN cells move laterally down to the base of the cerebellum to their adult location. A later wave of postmitotic neuronal cells leaves the chick VCP and moves toward the periphery to eventually become Purkinje (and probably Golgi) cells. A similar early embryonic origin of DN cells was seen in autoradiographic studies in rodents, followed by Purkinje (and maybe early Golgi) cells, while late Golgi cells and molecular layer cells (basket and stellate cells) originate postnatally (mouse: Miale and Sidman, 1961; Taber-Pierce, 1975; rat: Altman and Bayer, 1985, 1987e) from interstitial proliferative cells in the ventral white matter (Sotelo, 2004).

An even later embryonic wave of amniote cerebellar neuronal cells is generated in the URL (or germinal trigone), the ventricular epithelium posterior to the now already existing cerebellar plate and has been described in normal histological and autoradiographic studies to invade the uttermost periphery of the cerebellar plate in a tangential ventrolateral to dorsomedial (e.g., mouse; Miale and Sidman, 1961) or posterior to rostral (rat: Altman and Bayer, 1987e) direction. Since these neuronal progenitors will postnatally continue to proliferate and migrate ventrally to develop into (internal) cerebellar granule cells (as first seen around 1900 by Santiago Ramon y Cajal in embryonic human brains), this peripheral cell sheet is called external granular or germinal layer (EGL). Hanaway (1967) noted in the chick that the future EGL cells are produced in the entire mediolateral extent of the ventricular cerebellar plate (presumably the URL) and move radially out into the periphery instead of tangentially invading it. The EGL of the lateral cerebellar plate is formed first, preceding that of the medial one, which possibly explains the earlier observations of an apparent lateromedial tangential invasion. Later, the entire URL was described in amniotes to give rise to cells migrating tangentially (mostly in caudorostral direction) into a subpial EGL position (retrovirally labeled clones: Ryder and Cepko, 1994; chick-quail transplants, DiI labeling: Wingate and Hatten, 1999; Wingate, 2001; DiI: Gilthorpe et al., 2002). URL cells invading the subpial cerebellar plate use clues in the overlying meninges for organized migration and the resulting adult internal granular cell masses maintain the mediolateral topology of their rhombic lip origin (reviewed in Chédotal, 2010). Thus, the founder cells of the amniote subpial EGL arise in the (ventricular) proliferative zone of the URL (posterior part of the cerebellar plate) while the rostrally expanded VCP at the ventricular side of the cerebellar plate at this developmental time point may be considered a different ventricular zone. In contrast to the DN and Purkinje neurons formed by cell waves described above, the EGL cells remain mitotic during postnatal development and eventually give rise to an immense number of postmitotic neurons which migrate basally (e.g., Fujta, 1967; Alder et al., 1996; Zhang and Goldman, 1996; Komuro and Rakic, 1998a).

The proliferative activity of the EGL is regulated by differentiated Purkinje neurons via the Sonic Hedgehog signaling ( $\mathrm{SHH}$ ligand, which acts on $\mathrm{SHH}$ receptors (Patched, Smoothened) and transcription factors (Gli) expressed by EGL cells (Traiffort et al., 1998, 1999; review: Martí and Bovolenta, 2002; Sillitoe and Joyner, 2007; Chédotal, 2010). Thus, this represents a case of transit amplification (Kriegstein and Alvarez-Buylla, 2009). After entering the Vitronectin-rich premigratory zone, EGL cells become postmitotic (reviewed in Sotelo, 2004). During further cerebellar cortex development in amniotes, granule cells migrate ventrally in a radial glia guided fashion and will eventually cross the Purkinje cell layer to generate the densely populated deep adult internal granular layer (IGL; for reviews on this issue, see: Hatten, 1990, 1999; Hatten and Mason, 1990; Rakic, 1990; Hatten and Heintz, 1995; Hatten et al., 1997; Curran and D'Arcangelo, 1998; D'Arcangelo and Curran, 1998; Komuro and Rakic, 1998b; Goldowitz and Hamre, 1998; Voogd and Glickstein, 1998; Sotelo, 2004; Chédotal, 2010).

More recently, using an EGFP-expressing transgenic rat strain as source for transplants into wild type rats, the ventricular VCP was shown to produce all inhibitory cerebellar cell types (GABA-/ glycinergic) in the emerging cerebellar plate (Purkinje cells/Golgi and Lugaro cells of internal granule layer/basket and stellate cells of the molecular layer; Leto et al., 2006; recent review on adult cerebellar organization: Ito, 2006), as similarly found in mice (Weisheit et al., 2006). The VCP also generates the inhibitory fraction of deep cerebellar nuclei ( $\mathrm{DN}$; see more details below). In complement, the URL gives rise to an early stream of excitatory (glutamatergic) deep cerebellar nuclear cells (mouse: between E10-E12), which invade tangentially the subpial developing cerebellar plate (the socalled nuclear transition zone, a forerunner of the EGL) and then descend ventrolaterally to contribute to the DN shown with in situ hybridization (ISH) studies of transcription factor expressing genes $t b r 1, t b r 2$, and pax6 (Fink et al., 2006). Subsequently, the URL forms the EGL on the peripheral (subpial) side of the cerebellar plate (mouse: between E13 and E 16) which will continue to proliferate during postnatal development (mouse: 2 weeks) and it will produce myriads of excitatory (internal) granule and unipolar brush cells (Englund et al., 2006; Leto et al., 2006, review: Sillitoe and Joyner, 2007).

\section{MOLECULAR REVOLUTIONS NEW TOOLS}

At the turn of the millennium, sophisticated genetic studies extended rhombic lip and cerebellar development toward an improved understanding of the underlying genetic processes (mostly mouse, but see Wilson and Wingate, 2006 for chicken). The early active genetic network in the midbrain-hindbrain boundary (MHB) involving transcription factor-encoding genes ot 22 (midbrain), gbx2 (hindbrain), pax $2 / 5$ (MHB), and $f g f 8$ and wnt1 (both encode for proteins that can act as secreted morphogens) eventually leads to the formation of the cerebellar anlage defined by the expression of the homeodomain encoding genes engrailed 1/2 (Acampora et al., 2001; Liu and Joyner, 2001; Wang and Zoghbi, 2001; Wurst and Bally-Cuif, 2001; Sgaier et al., 2005). Genes with later continued expression in 
rhombic lip/cerebellar plate derivates may serve as "natural" markers to trace their fate (such as tbr1 for glutamatergic DN cells; see above). Most importantly, site specific recombinase systems (CreloxP and Flp-FTR) were introduced (Branda and Dymecki, 2004) to demonstrate the fate of cells expressing developmentally relevant genes expressed in the early cerebellar plate and rhombic lip after embryonic downregulation of this informative gene expression. Also, detailed comparisons of gene expression and phenotype in wild type and mutant organisms helped to decipher developmental mechanisms. An example is the paired-box/homeobox gene pax6, whose diverse roles in eye, nose, and cortex development are complemented by critical functions in rhombic lip and cerebellar development (Engelkamp et al., 1999). In the mouse, pax6 is strongly expressed between 12.5 and 13.5 days in the LRL and URL plus the latter's derivative, the EGL, but not in the remaining cells of the cerebellar plate. The pax6 expressing LRL progeny can be followed in anterior (AES) and posterior extramural streams (PES) toward their destination, i.e., reticulotegmental and basal pontine nuclei, lateral reticular/external cuneate nuclei, respectively, but not in the intramural stream (IMS) and its destination, the inferior olive (Figure 1A). In the pax6 homozygous loss of function mutant small eye (sey), the formation of basal pons (but not reticulotegmental nucleus and inferior olive) and LNR/ECN is impaired. Since in the sey mutant, proliferation in the LRL is not affected (premigratory cells actually accumulate there), and the Netrin 1 receptor DCC fails to be expressed in AES cells (in those few that migrate to form the reticulotegmental nucleus), pax6 may be associated with a function in migration, not proliferation. Proliferation is also not affected in the EGL of sey mutants: postmitotic cells accumulate in the premigratory zone of the cerebellar plate, but fail to migrate. In cells destined for the reticulotegmental pontine nucleus, pax6 function must be redundantly taken over by other gene(s).

\section{GENES INVOLVED IN INHIBITORY VS EXCITATORY NEURON DEVELOPMENT}

The basic Helix-Loop-Helix (bHLH)-factor-encoding gene ptf1a is expressed in the ventricular ventral cerebellar proliferation (VCP) and adult animals of its corresponding mouse mutant cerebelless have only a rudimentary cerebellum and show associated motor deficits (Hoshino et al., 2005; Hoshino, 2006). The adult cerebellar rudiment contains large glutamatergic (DN type) cells, but no GABAergic cells. However, during embryonic cerebellar plate development, the EGL does initially develop and glutamatergic markers (Calretinin) are expressed in its descendents (while GABAergic markers such as Calbindin remain absent). The EGL eventually disappears gradually during postnatal stages. Further, lineage tracing involving a Cre-recombinase-lac $Z$ strain allowing for the visualization of ptfla expressing cells and their progeny revealed that these cells only develop into cerebellar GABAergic and glial cells, but not glutamatergic cells (Hoshino et al., 2005). Thus, the primary effect in cerebelless mutants is that no GABAergic cells are formed from the ventricular cerebellar proliferation (VCP), while EGL formation and glutamatergic cell production from it is initially unaffected (large DN cells, see above). Later, presumably because of the missing mitogenic SHH signal from Purkinje cells (see above), the EGL disappears and granule cells and a functional cerebellum are not formed as a secondary consequence.
Interestingly, adult cerebelless mutants also lack (glutamatergic) inferior olive and pontine nuclei, which - although embryonically formed-disappear postnatally. This likely occurs as a secondary consequence because these precerebellar nuclei lack a cerebellar innervation target (see above). In the hindbrain, $p t f 1 a$ is also expressed in the ventral part of the LRL (apparently not affected in cerebelless) and cells descending from this area develop into all types of inhibitory (GABAergic, glycinergic) cells of the cochlear nuclei (Fujiyama et al., 2009), while glutamatergic cochlear nuclear cell types develop from the dorsal part of the LRL where another bHLH factor, the atonal homolog atoh1 or math 1 - and also pax6-are expressed. Surprisingly, inferior olivary neurons (although glutamatergic) develop mostly from the ptfla expressing cells in the posterior part of the ventral LRL (see below; Figures 1B,C).

In-depth analyses of mouse LRL revealed that wnt1 is expressed throughout the entire dorsoventral extent of the developing LRL, while math 1 and the bHLH gene neurogenin 1 (ngn1) are restricted to its dorsal and a ventrally adjacent part, respectively (Landsberg et al., 2005; see Figure 1C). Importantly, wnt1 is expressed in a decreasing dorsoventral gradient in the LRL, likely extending ventrally beyond the $n g n 1$ domain (Landsberg et al., 2005; Ray and Dymecki, 2009). Using Cre and Flp based fate mapping studies, Rodriguez and Dymecki (2000) and Landsberg et al. (2005) showed that mossy fiber-type precerebellar nuclei (BP, RTN, LRN, ECN) derive from the strongly wnt 1 and math 1 expressing dorsal LRL domain, while the climbing fiber system (IO) derives from weakly wnt1 and strongly ngn1 expressing ventral LRL domain. This is consistent with the reported $p t f a 1$ expression domain origin of IO (Hoshino et al., 2005; Yamada et al., 2007), although the ptfla domain may be even more ventral than that of $n g n 1$ in the posteroventral LRL (Ray and Dymecki, 2009), and thus, the IO cells might be molecularly parcellated (Landsberg et al., 2005; Ray and Dymecki, 2009). In any case, the anteroventral LRL has a ptf1a domain, but lacks $n g n 1$ expression - and gives rise to inhibitory cochlear nuclei cells (Fujiyama et al., 2009; see above). In pax6 mutant sey mice, a dorsal expansion of $n g n 1$ expression and concurrent regression of math1 expression is seen, accompanied by the disruption of extramural streams (mossy fiber cells) and an increase of migrating cells in the intramural stream (IMS) to the IO (Landsberg et al., 2005), consistent with an earlier report on the pax6 mutant sey phenotype (Engelkamp et al., 1999). This indicates that PAX6 acts in rhombic lip development and rhombic lip derived migration by limiting $n g n 1$ expression.

The bHLH gene olig 3 has a similar graded expression in the LRL as wnt1 does (Figures 1B,C covering dorsoventrally math1, $n g n 1$, and $p t f 1$ domains, with the gradient tapering out more slowly ventrally than that of wnt1 (Liu et al., 2008; Ray and Dymecki, 2009; Storm et al., 2009). Accordingly, olig 3 has a role in the development of both mossy and climbing fiber precerebellar nuclei as shown both by histochemical marker analysis of olig3 null mutant mice (Liu et al., 2008) and Cre based genetic fate mapping (Storm et al., 2009). As pointed out by Ray and Dymecki (2009), olig3 may represent the best and most inclusive LRL marker.

Further major insights came from fate mapping of cells depending on the bHLH factor MATH1, its encoding gene has been key to investigating rhombic lip and cerebellar development because of its exclusive expression in URL (and later EGL) and dorsal LRL (apart 
from anterior dorsal spinal cord, peripheral inner ear hair cells, and epidermal Merkel cells; Akazawa et al., 1995; Ben-Arie et al., 1997, 2000; Helms et al., 2000; Machold and Fishell, 2005; Wang et al., 2005). Using a math1-expression dependent Cre-recombinase strain in combination with a Cre-recombination mediated lac $Z$ reporter line, the above discussed origin of cochlear nuclei (excitatory cells) and of mossy fiber precerebellar systems from the strongly wnt1 expressing dorsal LRL (Landsberg et al., 2005), as well as the URL origin of the (excitatory) deep cerebellar nuclear cells and EGL of the cerebellum, was independently confirmed by determining the fate of math1 expressing progeny (Machold and Fishell, 2005; Wang et al., 2005). These studies also demonstrated that IO formation is independent of math1 expression. Beyond that, previously unknown math1 expressing rhombic lip derivatives were revealed in three (auditory related) lateral lemniscal nuclei, in the superior vestibular nucleus, in the parabrachial nuclear and in an isthmic complex (the latter two related to arousal; see more below on isthmic complex). A later analysis showed that in addition excitatory neurons (mostly glutamatergic, never GABA-/glycinergic) of the (auditory) superior olive, spinal, and medial vestibular nuclei, as well as primary somatosensory nuclei (principal and spinal trigeminal, medial cuneate, and gracile nuclei) and some breathing (Kölliker-Fuse nucleus, pre-Bötzinger complex, rostral ventral respiratory group) and bladder-control related (Barrington's nucleus) medullary nuclei derive from math1 expressing LRL (Rose et al., 2009). Although the vestibular nuclei also provide mossy fiber input to the cerebellum, they are not treated usually as precerebellar nuclei like the external cuneate and lateral reticular nucleus. The temporal succession of all subpopulations in each major migratory stream was also resolved, for example in the newly described rostral rhombic lip migratory stream (RLS) which forms the early subpial nuclear transition zone $(E 11,5)$ from which the isthmic and DN cells derive first before it subsequently gives rise to the EGL $(\mathrm{E} 13,5)$ and internal granule cells. Further, somatosensory spinal cord interneurons, which provide also mossy fiber input to cerebellar granule cells (as the precerebellar systems do), derive from the spinal continuation of the rhombic lip math1 expression domain.

An even finer temporal and anatomical analysis of the MATH1 dependent isthmic complex was obtained by using a inducible Cre-recombinase under the control of math 1 regulatory elements (Machold and Fishell, 2005). This study showed that the isthmic complex consists of the parabigeminal nucleus and the cholinergic pedunculopontine and laterodorsal tegmental nuclei, and further detailed the already described math 1 expressing progeny. Although not reported in that study, the mammalian parabigeminal and parabrachial nuclei also contain cholinergic cells (see discussion in Volkmann et al., 2010).

A normal expression study of wnt1 and a cell fate mapping study of transgenically labeled wnt1 expressing progeny in the mouse hindbrain (and midbrain) confirmed an LRL origin of cochlear nuclei and mossy fiber precerebellar systems, but not of the inferior olive (Nichols and Bruce, 2006). As discussed above, the IO was found to originate from the only weakly $w n t 1$ expressing ventral LRL (Landsberg et al., 2005). In addition, although wnt1 expression was previously not noted prior to mouse E11,5 in URL/EGL cells (Echelard et al., 1994), Nichols and Bruce (2006) reported beginning of wnt1 expression in URL cells from E10.5 onward and confirmed with wnt 1 expression mediated transgenic labeling the origin of the EGL (i.e., granule cells, deep cerebellar nuclei) from the URL. Interestingly, they described an anterior cellular migration (corresponding to the RLS of math1 expressing progeny, see above) via URL and EGL into the basal anterior rhombencephalon to form there at least part of the parabrachial and laterodorsal tegmental nuclei, indicating that the cholinergic math1 dependent groups (Machold and Fishell, 2005; see above) are also derivatives from wnt1 expressing precursors.

Beyond MATH1, the role of additional proneural bHLH factors has only begun to be unraveled. An ISH analysis of mouse bHLH genes ascl1 and neurogenin 1/2 noted their expression in the developing VCP or close to it, but an absence of expression of those genes in the URL. Thus, there is no overlap of the expression of these three genes with cerebellar math 1 domains between E10 and E13,5 and no co-expression between $n g n 1$ and $n g n 2$, but partial overlap of expression between $n g n 1 / 2$ with $a s c l 1$ and $p t f 1 a$ domains (Machold et al., 2007; Zordan et al., 2008). Thus, these bHLH factorencoding genes were interpreted to be related to the development of different inhibitory cell types. Indeed, ascl1 was recently shown to be co-expressed in VCP cells with ptf1a, with ASCL1 involved in Purkinje and inhibitory DN cell development (Kim et al., 2008). In contrast, $p t f 1 a / n g n 1$ co-expressing cells develop into Purkinje, Golgi and Lugaro cells (Lundell et al., 2009). In addition, ngn2 expression was shown to be active downstream of $p t f 1 a$, but not of ascll. The proneural factor coding gene neuro $D$ which is well established to act downstream of Neurogenins in the forebrain (reviewed in Osório et al., 2010) is required in the developing cerebellum for granule cell differentiation as shown in a comparison of wild type mice with a non-functional NeuroD mutant line (Miyata et al., 1999).

\section{RHOMBIC LIP DEFINITIONS}

Eventually, the suggestion arose to re-define and equal the rhombic lip with the extent of the math 1 expression domain bordering the rhombic fossa, including its derivatives (Wang et al., 2005). Although convenient at first sight, such a definition hinders the understanding of this complex structure at the functional systems level. The $p t f 1 a / n g n 1$ expressing ventral part of the dorsal rim of the rhombic fossa and the dorsally adjacent math 1 domain have in common that they both are the source of long distance tangential cellular migrations leading to the formation of inferior olive/inhibitory cells of cochlear nuclei and mossy fiber precerebellar nuclei/excitatory cells of cochlear nuclei, respectively. Functionally not directly cerebellar/auditory-related systems, such as the locus coeruleus, do not arise from this ventral rhombic lip territory. Instead they originate more ventrally as shown with fate mapping studies using grafting (quail-chick) and mouse brain gene expression analysis visualizing noradrenergic cell markers (dopamine- $ß$-hydroxylase and transcription factors Phox $2 a / b$; Aroca et al., 2006). This more ventral origin was confirmed in a study combining $w n t 1$ expression mediated transgenic labeling with tyrosine hydroxylase immunostaining (for catecholaminergic cells) where no cells in the mouse locus coeruleus were double-labeled (Nichols and Bruce, 2006). In contrast, Lin et al., 2001 claimed that the chick locus coeruleus originates from the EGL. Be that as it may, all amniote LRL derivatives share the functional context of being closely involved in cerebellar or auditory circuitry. We therefore use dorsal and ventral rhombic lip (dLRL/vLRL), respectively, for the math1 and ptf1a/ngn1 
expressing portions of the LRL. The URL/EGL and the ventricular VCP are comparable to at least the anterior dorsal and ventral LRL, respectively, regarding inhibitory/excitatory cell production, with the additional contribution of the URL to the cholinergic isthmic groups just discussed. However, as explained above, the early separable VCP is terminologically treated as different from the URL (germinal trigone), as the VCP does not show the long distance migratory behavior of its descendant cells as the vLRL does.

\section{ANAMNIOTE PATTERNS STARTING POINTS}

We will now discuss existing evidence and provide new insights into similar and dissimilar patterns of rhombic lip and cerebellar development in anamniotes, particularly in the zebrafish. A natural starting point is to establish whether adult structures known to develop from rhombic lip and ventral cerebellar proliferation (VCP) in amniotes are present in zebrafish. A cerebellum with a three-layered cortex, including the major inhibitory and excitatory (glutamatergic) cell types, is present in the zebrafish (Miyamura and Nakayasu, 2001; Mikami et al., 2004; Bae et al., 2009) as in all gnathostome vertebrates (but absent in lampreys and myxinoids, Wullimann and Vernier, 2007). Deep cerebellar nuclei in teleosts are represented by eurydendroid cells, which are large excitatory cells in the Purkinje cell layer (Lannoo et al., 1991; McFarland et al., 2008; Bae et al., 2009). Thus, teleostean eurydendroid cells apparently fail to migrate into the deep of the cerebellum. They receive (inhibitory) Purkinje cell input and form the axonal output of the cerebellum (for example in the goldfish; Ikenaga et al., 2005). In the zebrafish, cholinergic isthmic nuclei exist (i.e., nucleus isthmi, secondary gustatory, and superior reticular nucleus, refered to below as the teleostean cholinergic isthmic complex; Clemente et al., 2004; Mueller et al., 2004), which are homologous to parabigeminal, parabrachial, and pedunculopontine-laterodorsal tegmental nuclei. For lack of connectional information in the zebrafish, the closely related goldfish or carp may be mentioned for the presence of an inferior olive which represents the sole cerebellar climbing fiber origin (Xu et al., 2008) and of mossy fiber-type precerebellar nuclei (lateral reticular nucleus; lateral cuneate nucleus; Wullimann and Northcutt, 1988) as well as of hearing related primary sensory nuclei (McCormick and Braford, 1994; McCormick and Hernandez, 1996). In contrast, a pons does not exist in anamniotes, including teleosts. However, do the other mentioned structures share a rhombic lip/VCP origin in teleosts? An additional immediately interesting question is whether the primary central lateral line nucleus (medial octavolateralis nucleus, MON; New et al., 1996) is a rhombic lip derivative with excitatory cells derived from atoh1 expressing progenitors similar to the amniote cochlear nuclei. All anamniotes - except for strictly terrestrial amphibians - have this additional sensory organ and the related central processing apparatus which is entirely lost in amniotes. However, LRL derived structures have not been revealed by genetic fate mapping in teleosts so far.

\section{EMBRYONIC AND LARVAL GENE ACTIVITY IN ZEBRAFISH RHOMBIC LIP AND CEREBELLAR PLATE}

As in amniotes, the dorsal edges of the zebrafish alar plate rhombencephalon are laterally displaced upon formation of the fourth ventricle and define in transverse view a V-shaped rhombic fossa only covered by the roof plate (see Distel et al., 2006; their Movie 4). Furthermore, the early cerebellar plate develops between 24 and $48 \mathrm{~h}$ in the most anterior dorsal rhombencephalon (rhombomere 1) as bilateral, elevated flaps which eventually will cover the ventricle (Figures 2A, $\mathbf{A}^{\prime}$ ). However, the anatomical resolution does not allow identifying a structure comparable to the amniote germinal trigone/ URL at the posterior margin as different from the proper cerebellar plate (Mueller and Wullimann, 2005). How about diagnostic gene expression patterns? Because of an additional whole genome duplication in early ray-finned fish (actinopterygians), modern teleosts such as the zebrafish have three paralogous atoh1 (math1 homolog) genes, namely atoh1a (atoh1.1), atoh1b (atoh1.2), and atoh1c (Kim et al., 1997; Jászai et al., 2003; Adolf et al., 2004; Wang et al., 2009; Kani et al., 2010). The atohla and atoh1b (not shown) gene expression patterns (Figures $2 \mathbf{A}^{\prime}, \mathbf{B}^{\prime}$ and $3 \mathbf{B}$ ) are very similar from 1 to 2.5 days: expression domains are seen in the fused dorsal neural tube of the anterior spinal cord and most posterior hindbrain, then outline in the more rostral hindbrain the shape of the laterally displaced medullary edges (lower rhombic lip) and form in the most anterior hindbrain, where the cerebellar plate develops, a transverse bridge of expression (Köster and Fraser, 2001a), defining a URL by molecular means (see Discussion below). In addition, a strong expression is seen in the developing valvula cerebelli, an anterior part of the midline cerebellum only present in ray-finned fish (Figure 3B). After 2.5 days, atoh $1 a$ and atoh $1 b$ expression are fastly downregulated in LRL and URL, with atoh $1 b$ expression persisting longer in the URL, and both gene expressions are upheld in the valvula (Figure 3C). In contrast atoh1c expression is never seen in the LRL, but starts late (at around 2 days) to be strongly expressed in the valvula and URL (Kani et al., 2010), where it remains active in the larva beyond 9 days (Figures 2C-F and 3D).

As in amniotes, zebrafish wnt1 expression is not restricted to the URL and LRL, but it is expressed between $16 \mathrm{~h}$ postfertilization (hpf) and 2 days beyond the dorsal rhombencephalon in the most dorsal mesencephalon and in the MHB, with an initial gap in the region of the cerebellar plate (Elsen et al., 2008). However, around $30 \mathrm{hpf}, w n t 1$ expression also is seen in the cerebellar plate (Lekven et al., 2003; McFarland et al., 2008).

Expression of the zebrafish $p f 1 a$ gene starts around $32 \mathrm{hpf}$ and is seen at least up to 5 days, in dorsal whole mount views in locations superficially similar to the URL and LRL expression domains of the atoh1a gene (Kani et al., 2010). However, in sagittal sections, it becomes clear that ptfla is restricted to the ventricular cerebellar proliferation (VCP) and extends later into the valvula, while atoh1 gene expression is in a non-overlapping superficial/subpial position (Kani et al., 2010), already indicating that many atoh1 expressing cells are in a comparable position of an amniote EGL (Figure 1F). The expression of ptf1a in the LRL is ventral to that of atoh1a (A. Babaryka, R. W. Köster, personal observation).

As discussed above, the first mouse math 1 and wnt 1 dependent URL cells that invade the cerebellar plate subpially will migrate via the RLS and form the cholinergic isthmic groups (PBGN/PBRN/ PP-LDTN) and deep cerebellar nuclei (DN; see Figure 1A); this is followed by the establishment of the EGL/inner granule cells (Machold and Fishell, 2005; Wang et al., 2005; Nichols and Bruce, 2006). Confocal time-lapse imaging using embryos of a zebrafish transgenic wnt1-Gal4-GFP strain revealed that an early migration 

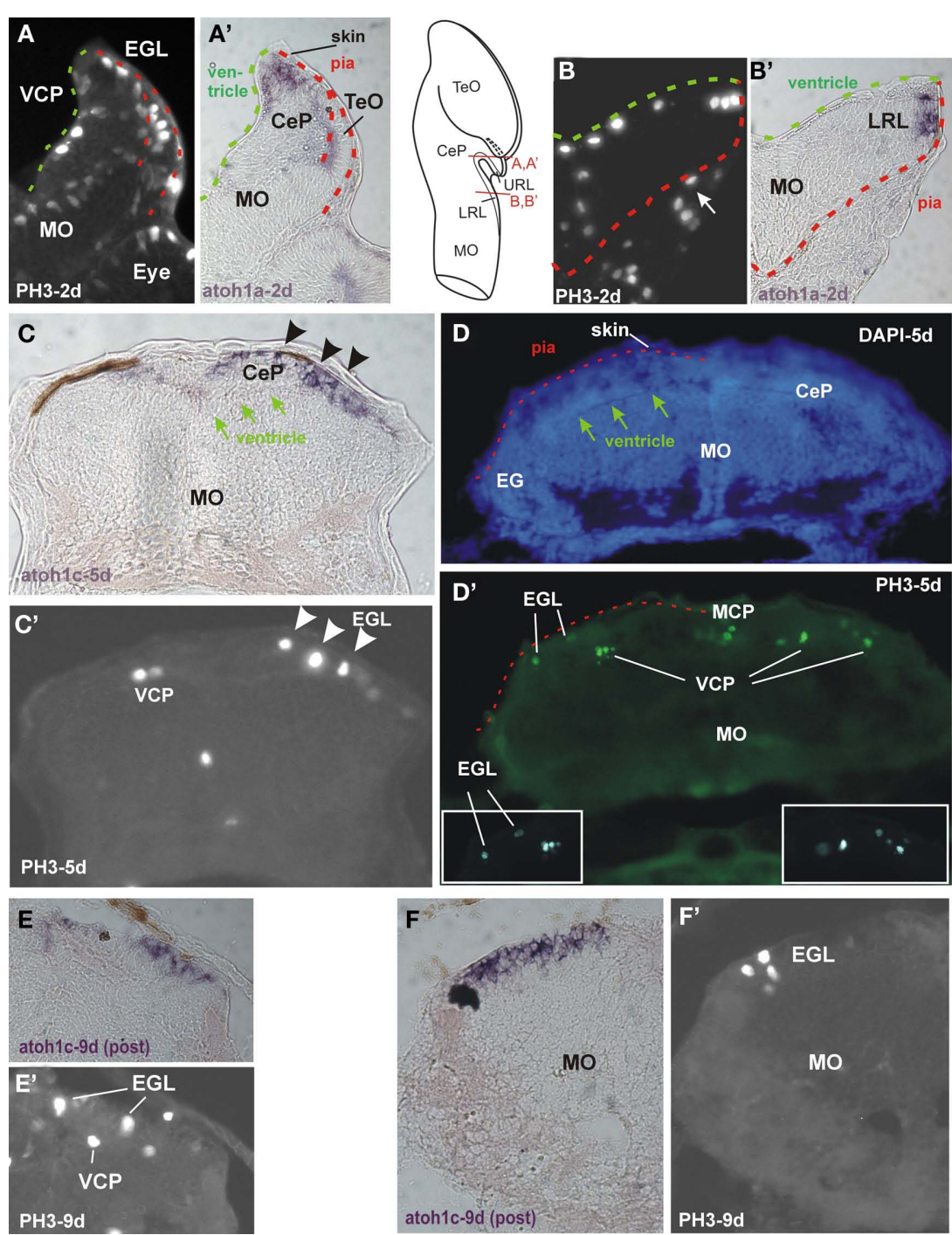

FIGURE 2 | Proliferation shown with phosphohistone 3-immunohistochemistry (PH3-IHC) and expression of bHLH genes atoh1a and atoh $1 c$ in zebrafish cerebellar plate (CeP; $\left.A, A^{\prime}, C, C^{\prime}, D^{\prime} D^{\prime}, E, E^{\prime}, F, F^{\prime}\right)$ and lower rhombic lip (LRL; B, B') transverse sections. (A) $\mathrm{PH} 3-\mathrm{HHC}$ in $\mathrm{CeP}$ at 2 days. Note that proliferation in $\mathrm{CeP}$ is both on the ventricular (green dashed line) and pial (red dashed line) side. ( $\mathbf{A}^{\prime}$ ) Identical section shows atoh1a ISH and overlap with both proliferative zones. (B) PH3-IHC in LRL at 2 days. Note that proliferation is only on ventricular side (green dashed line), not on pial side (red dashed line). More lateral PH3-positive cells are in connective tissue outside of brain (arrow). (B') Identical section shows atoh1a ISH to overlap with $\mathrm{PH} 3$ cells at ventricle, and to extend more peripherally. (C) Expression of atoh $1 \mathrm{c}$ at 5 days is mostly periphal (note arrows indicating ventricle) forming an EGL (arrowheads) and colocalizes with $\mathrm{PH} 3$ positive cells (shown in identical section in $\left(\mathbf{C}^{\prime}\right)$; arrowheads; left side shows $\mathrm{PH} 3$ positive cells in atoh1c negative ventral cerebellar proliferation). (D) DAPI stain and ( $\mathbf{D}^{\prime}$ ) PH3-IHC stain (identical section) demonstrate that proliferative cells are present in ventricular cerebellar proliferation (VCP) and in external granular layer (EGL). Insets show PH3 positive cells in EGL adVCP at a different focus. Dashed red line indicates pial surface of brain with skin above it. Arrows denote ventricle. (E, $\left.\mathbf{E}^{\prime}\right)$ and $\left(\mathbf{F}, \mathbf{F}^{\prime}\right)$ demonstrate that an $E G L$ persists into later larval development, at least 9 days. Note in particular in $\left(\mathbf{F}^{\prime}\right)$ how atoh $1 \mathrm{C}$ expression is at the periphery of the cerebellar plate, that proliferative $\mathrm{PH} 3$ cells are restricted to most peripheral EGL and that proliferation is absent in the rest of the hindbrain at that stage. Methodological details will be provided elsewhere. $\mathrm{CeP}$, cerebellar plate; EGL, external granular (or germinative) layer; 10 , inferior olive: $\mathrm{LRL}$, lower rhombic lip; MO, medulla oblongata; TeO, tectum opticum; VCP, ventral (or ventricular) cerebellar proliferation (ventricular germinal matrix). between 24 and 48 hpf (Volkmann et al., 2010) precedes granule cell migration from the EGL, which only starts around $48 \mathrm{hpf}$ (Volkmann et al., 2008). In particular, zygotes of this transgenic wnt1-reporter strain were injected with an UAS:mCherry construct to allow for precise visualization of this early migration. These wnt1expressing cells co-express atohla and were shown to arise from proliferative cells (in an area indicated in Figure $1 \mathrm{~F}$ with an $\mathrm{X}$ ), move out into the subpial periphery of the cerebellar plate, before they migrate ventrally into the tegmentum of the most anterior rhombencephalon. Furthermore, this tegmental cluster exhibits expression of cholinergic and glutamatergic markers (Volkmann et al., 2010) and has differential and characteristic axonal projections to the optic tectum and the diencephalon indicating that this teleostean cholinergic isthmic complex includes the homologs of the cholinergic isthmic groups of mammals (Volkmann et al., 2010; summarized in Figure 7). It is also interesting that no tbr1/tbr2 expressing cells 


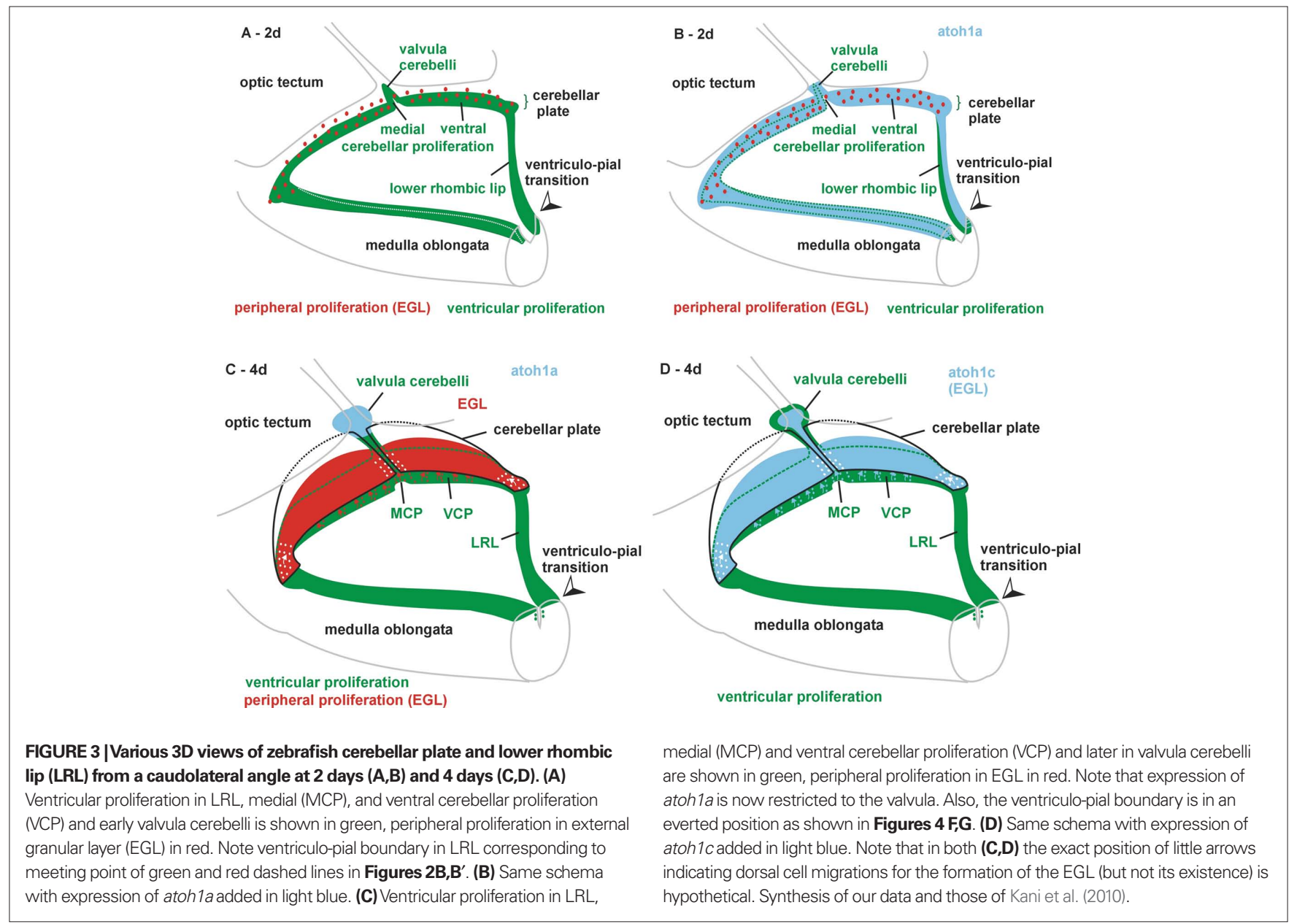

are seen in the migrating isthmic population (Volkmann et al., 2010), consistent with the fact that the eurydendroid cells, which are homologous to amniote DN, remain within the cerebellar cortex (Lannoo et al., 1991; McFarland et al., 2008; Bae et al., 2009).

\section{THE ZEBRAFISH UPPER RHOMBIC LIP}

Which region in the zebrafish brain corresponds to the amniote atoh positive cell producing URL (germinal trigone)? Köster and Fraser (2001a) have shown that atohla expression in the zebrafish is initiated at about $18 \mathrm{hpf}$ in the cerebellar plate along the most dorsal ventricle (indicated by an $\mathrm{X}$ in Figure $\mathbf{1 F}$ ) and then spreads into the subpial cerebellar plate periphery covering the entire cerebellar primordium up to the MHB by $20 \mathrm{hpf}$. This precedes by far the expression of $p t f 1 a$, which only starts around $32 \mathrm{hpf}$ more ventrally (in the VCP), but directly adjacent to the atoh 1 a expression domain and this non-overlapping expression is maintained throughout development (A. Babaryka, R. W. Köster, personal observations; Kani et al., 2010). At the same time, atoh1b expressing cells and, in addition, from 2 days on into later larval life atoh $1 c$ expressing cells, are in the subpial periphery of the cerebellar plate with the ptf1a gene non-overlappingly expressed in the VCP (Kani et al., 2010, their Figure 1). In comparison to amniotes, these subpial atoh1 cells correspond to an EGL and their ventricular point of origin as described above is in the caudal meeting point of ventral ptfla positive zone and atoh1-positive subpial zone (the X in Figure 1F). This has been shown by in vivo time-lapse studies that observed atoh1a expressing cells proliferating at the dorsal cerebellar ventricle (Distel et al., 2010). Subsequently, atoh1/wnt1 expressing URL cells move rostrally and migrate ventrally. Early URL emigrating cells give rise to neurons of tegmental hindbrain nuclei while later arising neurons will form the inner granular layer (Köster and Fraser, 2001b, 2006; Volkmann et al., 2008; Rieger et al., 2008; Kani et al., 2010; Volkmann et al., 2010).

\section{THE ZEBRAFISH EXTERNAL GRANULAR LAYER}

Thus, the subpial atoh 1 expressing cells in the zebrafish from 2 days on are in a position comparable to the amniote EGL and they originate from the most dorsal cerebellar plate ventricle (which corresponds to the amniote germinal trigone). For the recognition of an EGL, a critical issue is whether proliferation takes place during these developmental events not only at ventricular, but also on the subpial side of the zebrafish cerebellar plate. Phosphohistone 3 (PH3) immunohistology clearly shows that LRL and URL behave differently in this respect. Whereas the zebrafish LRL at 2 days shows $\mathrm{PH} 3$ positive cells only at the ventricular side (Figure 2B; note that pial and ventricular surface are indicated by stippled green and red lines, respectively, in all panels of this figure), with atohla positive cells extending radially out into the pial periphery (Figure $2 \mathbf{B}^{\prime}$ ), 

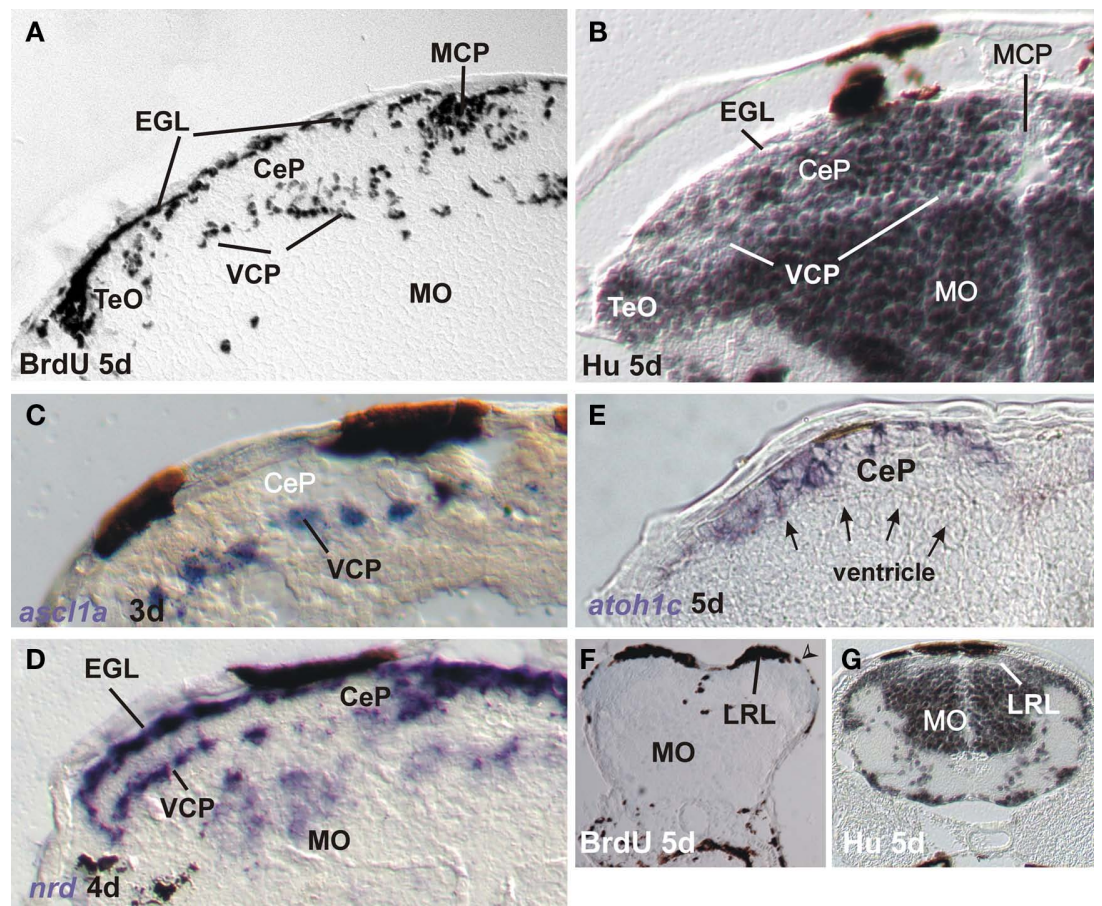

FIGURE 4 | Markers for proliferation and neurogenesis in zebrafish cerebellar plate (A-E) and [lower rhombic lip, LRL $(G, F)]$ shown in transverse sections. (A) Proliferation in ventral and medial cerebellar proliferation and external granular layer shown with BrdU saturation labeling (see text). (B) Differentiation in cerebellar plate shown with Hu immunohistochemistry. Note complementarity of label to BrdU pattern. (C) Ventral cerebellar expression of proneural gene asc/1a. (D) Ventral and dorsal cerebellar expression domains of bHLH neuroD. Modified from Mueller and Wullimann (2002) and Wullimann and Mueller (2002). (E) Dorsal cerebellar expression of bHLH atoh1c. Note position of ventricle (arrows). (F) Proliferation at LRL level shown with BrdU saturation label. Note position of ventriculo-pial transition (arrowhead). (G) Differentiation at LRL level shown with Hu immunohistochemistry. Note Hu-free LRL. Both modified from Mueller and Wullimann (2005). CeP, cerebellar plate; EGL, external granular (or germinative) layer; $1 \mathrm{O}$, inferior olive; $\mathrm{LRL}$, lower rhombic lip; $\mathrm{MCP}$, middle cerebellar proliferation; $\mathrm{MO}$, medulla oblongata; $\mathrm{TeO}$, tectum opticum; VCP, ventral (or ventricular) cerebellar proliferation (ventricular germinal matrix). the situation is different in the cerebellar plate. Here, proliferation is located both at the periventricular as well as at the subpial side (Figure 2A) and atoh1a extends from ventricularly located cells out into the pial periphery (Figure 2A' $\mathbf{A}^{\prime}$ ). In later larvae between 5 and 9 days atoh1c expression is seen to reach the periphery of the cerebellar plate and that some atohlc positive cells at the pial periphery still do co-express $\mathrm{PH} 3$ (Figures 2C, $\mathbf{C}^{\prime}, \mathbf{E}, \mathbf{E}^{\prime}, \mathbf{F}, \mathbf{F}^{\prime}$ ). Of course, proliferation ( $\mathrm{PH} 3$ reactivity) is also seen in the VCP (Figures $2 \mathrm{D}, \mathbf{D}^{\prime}, \mathbf{E}, \mathbf{E}^{\prime}$ ). This shows that in the zebrafish cerebellar plate subpially migrated atoh 1 cells continue to proliferate into larval life, meeting one of the critical characteristics of an EGL. The LRL in later larval zebrafish brain development is more everted than at 2 days, but the ventriculopial transition point is still clearly identifiable (Figures 3 and 4G,F).

Previous studies of the early zebrafish cerebellar plate (3-5 days) development using proliferating cell nuclear antigen (PCNA) immunohistochemistry and BrdU had already provided evidence for distinct proliferative layers in the zebrafish VCP and in a subpial position (suggestive of an EGL) with postmitotic cells in between (Mueller and Wullimann, 2002; Figures 4A,B and 5). The latter were demonstrated with immunohistochemistry for $\mathrm{Hu}$ proteins (Figures $4 \mathrm{~B}$ and 5) which mark early differentiated neuronal cells (Marusich et al., 1994). Further, expression of proneural bHLH genes asclla (Wullimann and Mueller, 2002) and neuroD (nrd; Mueller and Wullimann, 2002) supported this early cerebellar plate organization. Expression of asclla

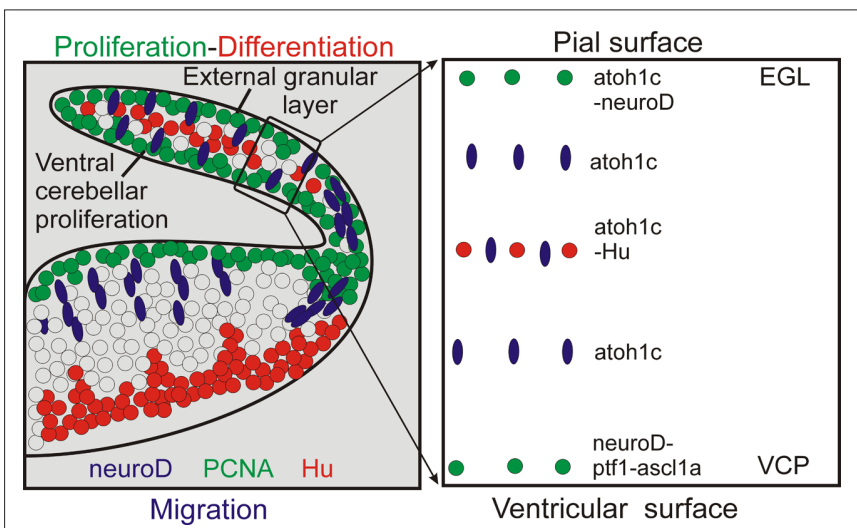

FIGURE 5 | Schema summarizes neurogenesis in zebrafish cerebellar plate. Left panel: Interpretative sketch based on localization of cellular marker in zebrafish cebellar plate as shown in Figure 4. GABA as shown in Mueller and Wullimann (2006). Right panel: summary of markers at various dorsoventral levels of zebrafish cerebellar plate. Data as shown in left panel and compiled from Kani et al., 2010 (ptf1).

is only seen in the zebrafish VCP (Figures 4C and 5), whereas nrd is present in both the VCP and EGL (or close to them, Figures $4 \mathrm{D}$ and 5), leaving the sandwiched $\mathrm{Hu}$-positive cerebellar area in between 

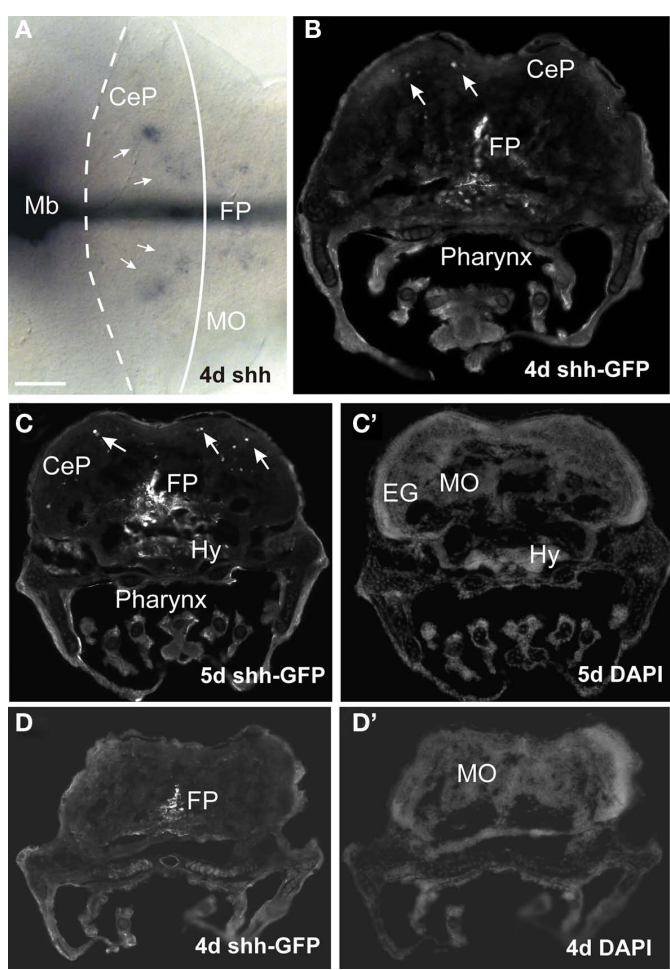

FIGURE 6 | Expression of sonic hedgehog in larval zebrafish cerebellar plate. (A) Whole mount shows midbrain and hindbrain expression of shh (ISH, performed as described in Volkmann et al., 2010). (B-D) Transverse sections at cerebellar plate $(\mathbf{B}, \mathbf{C})$ and medullary (D) levels from transgenic $\mathrm{Tg}$ (2.4shha-ABC:GFP)sb15 zebrafish (line originally published as $\mathrm{Tg}$ (2.2shh:gfpABC\#15) by Shkumatava et al., 2004). Note GFP+ cells in floor

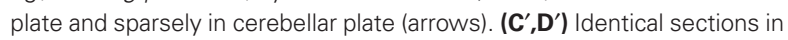
DAPI stain. Methodological details will be reported elsewhere. CeP, cerebellar plate; EG, eminentia granularis; FP, floor plate; Hy, hypothalamus; $\mathrm{Mb}$, midbrain; $\mathrm{MO}$, medulla oblongata. free of expression. In contrast, atoh1c at that developmental time is expressed at the subpial side only (EGL plus additional cell layers ventrally, Figures 4E and 5). Since in the vertebrate forebrain asclla is involved with GABAergic and $n r d$ with glutamatergic cell development, respectively (see discussion in Osório et al., 2010), these early studies already indicated the possibility that GABAergic cells are generated in the zebrafish VCP and glutamatergic cells in the EGL (Mueller and Wullimann, 2002; Wullimann and Mueller, 2002). GABA immunopositive cells are observed in the zebrafish cerebellar plate beginning with 3 days (Mueller et al., 2006). As discussed above, mouse $a s c l$ is indeed expressed downstream of ptfla in VCP cells and involved in Purkinje cell development whereas mouse neuroD expression is involved in granule cell development. Intriguingly, zebrafish neurogenins (its two homologs $n g n 1$ and $n g n 2$ are apparently involved in GABAergic cell development in the mouse cerebellum, see above) were not observed to be expressed during zebrafish URL and LRL development so far (Mueller and Wullimann, 2003). Recent studies used transgenic zebrafish lines expressing reporter fluorescent proteins under the control of regulatory elements of proneural genes ptf1a,wnt1, atoh1a, and olig2 (McFarland et al., 2008; Volkmann et al., 2008, 2010; Distel et al., 2010; Kani et al., 2010). This work established the fate of VCP and EGL zebrafish cerebellar plate cells showing essentially correspondence to the situation seen in the mammals (see above). During 2-5 days of zebrafish cerebellar plate development, atoh1a:EGFP cells give first rise to the tegmental cholinergic complex, followed by the formation of inner granule cells. These studies cleary demonstrate that the atoh 1 a expressing cells also begin to express the proneural gene $n r d$ already close to the EGL and $n$ rd positive cells later accumulate in the cerebellar inner granule layer, thus showing their subpial origin from atoh 1a expressing progenitors (Volkmann et al., 2008). It was furthermore shown in a BrdU assay that proliferation does occur in the EGL during this developmental process (Kani et al., 2010). In contrast, ptfla:EGFP cells are shown to originate in the VCP and migrate dorsally to form Purkinje cells

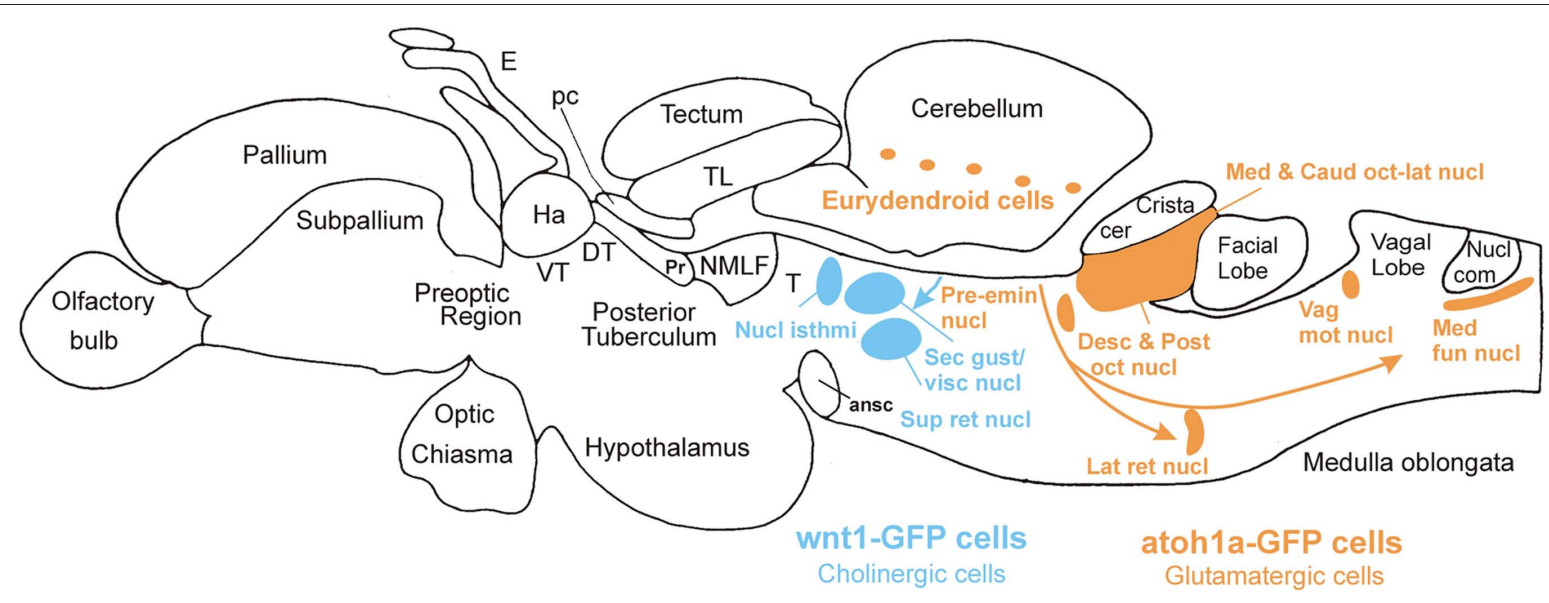

FIGURE 7 | Lateral view of adult zebrafish brain indicating major brain divisions and derivatives of wnt1 expressing cerebellar plate/upper rhombic lip cells (blue) in rostral hindbrain (cholinergic nuclei) and hypothesized derivatives of atoh1a expressing cells (orange) from lower rhombic lip in posterior hindbrain. ansc, ansulate commissure; Crista cer, crista cerebellaris; Desc and Post oct nucl, descending/posterior octaval nuclei; DT, dorsal thalamus; E, epiphysis; Ha, habenula; Lat ret nucl, lateral reticular nucleus; Med fun nucl, medial funicular nucleus; NMLF, nucleus of medial longitudinal fascicle; Nucl com, nucleus commissuralis Cajal; Pc, posterior commissure; Pr, pretectum; Pre-emin nucl, pre-eminential nucleus; Sec gust/visc nucl, secondary gustatory/viscerosensory nuclei; Sup ret nucl, superior reticular nucleus; T mesencephalic, tegmentum; $T L$, torus longitudinalis; Vag mot nucl, vagal motor nucleus; VT, ventral thalalmus. 

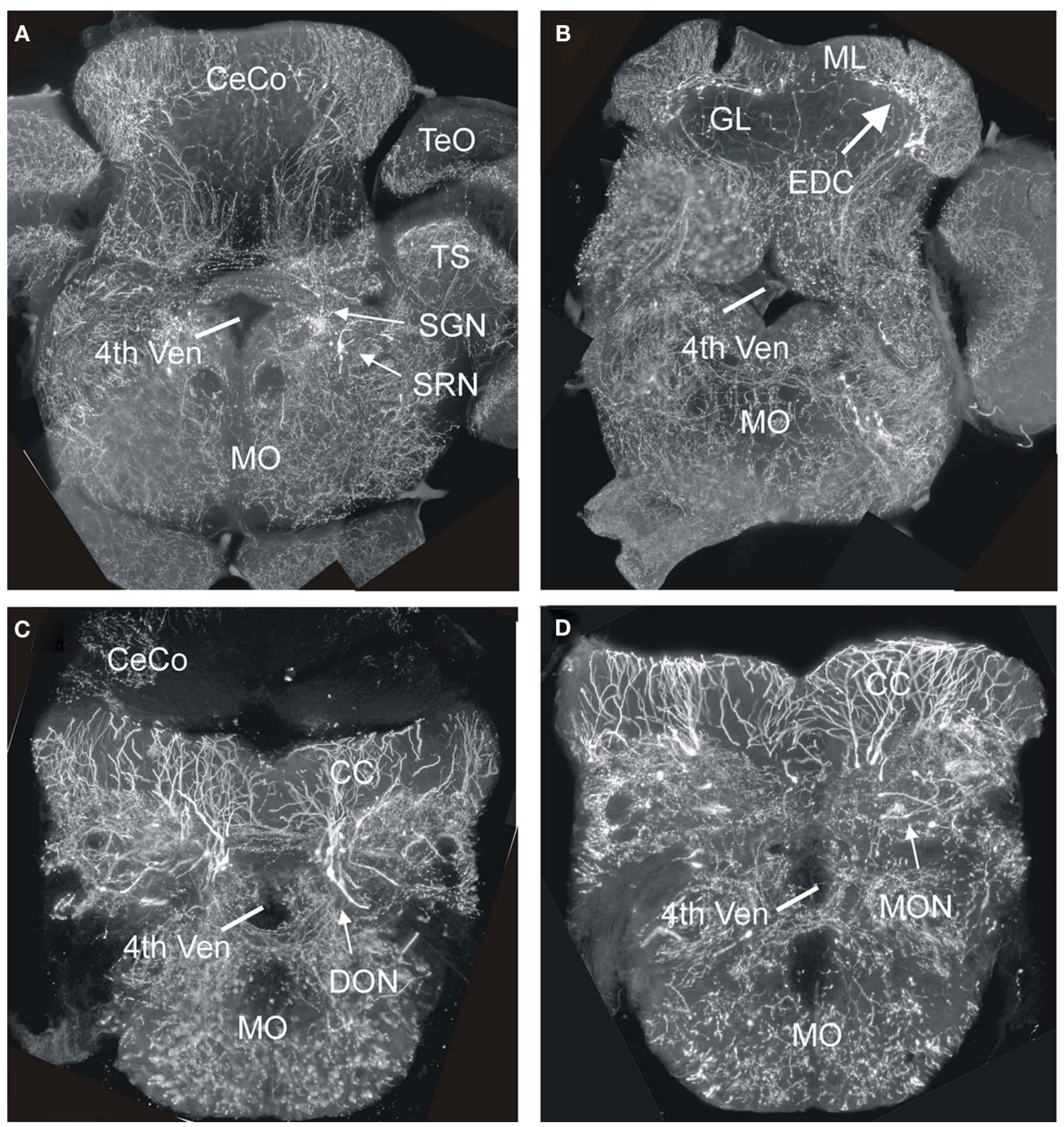

FIGURE 8 | Four transverse sections of the hindbrain from adult transgenic Tg(atoh1a: Gal4TA4) $)^{\text {hrm2 }} \times \operatorname{Tg}(4 \times U A S: G F P)^{\text {hzm3 }}$ zebrafish from rostral (A) to caudal (D) showing various GFP expressing cells in nuclei known in amniotes (as far as present) to derive from lower rhombic lip. Note that most fluorescent label shows fibers, not somata. The generation of these transgenic strains has

been described in detail in Distel et al., 2009, 2010). 4th ven, fourth ventricle; CC, crista cerebellaris; $\mathrm{CeCo}$, cerebellar corpus; DON, descending octaval nucleus; $\mathrm{EDC}$, eurydendroid cells; $\mathrm{GL}$, granular layer; $\mathrm{ML}$, molecular layer; $\mathrm{MO}$, medulla oblongata; MON, medial octavolateralis nucleus; SGN, secondary gustatory nucleus; SRN, superior reticular nucleus; TS, torus semicircularis.

(and likely other inhibitory cerebellar cell types; Kani et al., 2010). A curious difference to the situation in the mouse was seen with respect to the origin of zebrafish eurydendroid cells, the homolog of the mammalian deep cerebellar nuclei. Early zebrafish cerebellar cells expressing the proneural factor-encoding olig2 gene will give rise to eurydendroid cells (McFarland et al., 2008; Kani et al., 2010). Unlike in mammals, the vast majority of these (excitatory) cells does not derive from the atoh 1 expressing URL (although some do, Kani et al., 2010), but instead from the dorsal part of the ptfla expressing VCP, immediately ventrally adjacent to the ventricular atohla expression domain. This fact may serve to explain why teleost eurydendroid cells behave like VCP derived Purkinje neurons. Future eurydendroid cells migrate only over short distances to populate the Purkinje cell layer rather than migrating over long distances into a deep cerebellar nuclear position like the math1 expressing mammalian DN. A slight shift in atohl or ptfla expression could have modulated the migration behavior and final position of these DN homologous cells in teleosts. Correlated with this is an additional difference regarding the neurotransmitter type, as descendants of ptfla expressing cells only give rise to GABAergic cells in mammals (see above), while in zebrafish ptfla expressing cells also contribute to glutamatergic eurydendroid cells. Possibly the nrd expression in the zebrafish VCP (Mueller and Wullimann, 2002), which is not seen in the mouse, may be related to the production of these excitatory cells from the zebrafish VCP.

In contrast to the above reports, Chaplin et al. (2010) have argued that the zebrafish has no EGL comparable to amniotes because of absence of (1) subpial proliferation, (2) ventral migration of atoh1 expressing cells, (3) complete subpial coverage of the cerebellar 
plate with atoh 1 cells in later larval stages, and most importantly, (4) absence of markers indicating the presence of transit amplification of the EGL proliferative activity via a SHH signal from Purkinje cells. The first claim is clearly refuted by data discussed above (Kani et al., 2010; data shown in Figure 2, summarized in Figure 3). In fact, Chaplin et al.'s (2010) own data (their Figure 2G) shows that both a VCP and EGL layer of PH3 positive cells is seen in the cerebellar plate. Similarly, the ventral migration of atoh1 a cells has been amply documented (Köster and Fraser, 2001a, 2006; Volkmann et al., 2008; Kani et al., 2010). However, it is true that in later larval stages, the cerebellar plate is only covered caudally by proliferative atohlc positive cells (only this paralog is relevant), which would be different from the ubiquitous subpial presence of an EGL in the postnatal mouse. However, a SHH mediated transit amplification of EGL proliferation in the zebrafish as seen in mammals during cerebellar development gains support by our finding of shh expression in the zebrafish cerebellar plate at 4-5 days using ISH or transgenic fish in which GFP expression is mediated by regulatory elements of shh (Figure 6). Thus, atoh 1 positive cells generated in the ventricular zone of the caudal URL invade the caudal cerebellar plate subpially, continue to proliferate there and give rise to cell migrations to the anteroventral tegmentum (cholinergic complex) and later inner granule cells, as seen in mammals. In conclusion, there is an EGL also in zebrafish.

\section{THE ZEBRAFISH LOWER RHOMBIC LIP}

Finally, we consider the zebrafish LRL and its potential derivatives. An immunohistochemical study on the distribution of PAX6 proteins in the zebrafish brain indicated that cerebellar and LRL domains are similar to the situation in the mouse (Wullimann and Rink, 2001). Importantly, a stream of PAX6 positive ventrally migrating cells was observed, indicative of a rhombic lip contribution to ventral medullary precerebellar nuclei. Detailed studies using transgenic zebrafish to show the fate of atoh or wnt 1 dependent cells are missing so far and no zebrafish hindbrain structure has been clearly shown to be derived from the LRL by fate mapping analysis. However, the use of a transgenic zebrafish $\operatorname{Tg}$ (atoh1a:Gal4TA4) $)^{\text {hrm2 }}$ line to identify GFP expressing cells in the adult hindbrain produced some potentially exciting results. We found single GFP expressing cells in these brains in cerebellar eurydendroid cells (Figures 8B and 7 ), as well as in brain nuclei representing the cholinergic complex (Figures 8A and 7), in primary (descending and posterior) auditory nuclei (Figures 8C and 7), in the lateral reticular and in cells lateral to the medial funicular nucleus, the latter possibly corresponding to the lateral cuneate nucleus, which both project to the adult teleost cerebellum (Wullimann and Northcutt, 1988), in the lateral line primary mechanosensory (medial and caudal) octavolateralis nuclei (Figures 8D and 7), in the lateral line related pre-eminential nucleus and also in the vagal motor area (Figure 7). Since the location of most of these GFP labeled cells in the adult zebrafish brain is con-

\section{REFERENCES}

Acampora, D., Gulisano, M., Broccoli, V., and Simeone, A. (2001). Otx genes in brain morphogenesis. Prog. Neurobiol. 64, 69-95.

Adolf, B., Bellipanni, G., Huber, V., and Bally-Cuif, L. (2004). atoh1.2 und beta3.1 are two new bHLH-encoding

sistent with an origin from atoh1a expressing progenitors similar to the situation in amniotes, it is tempting to conclude that the label reflects their origin in embryonic/larval atoh 1 a expressing URL and LRL cells. In addition, the data indicate that structures of the lateral line system, which are functionally similar to the auditory system, do also derive from the LRL in anamiotes. However, these data have to be treated with caution, since it is highly likely that the GFP cells might alternatively represent descendants of adult atoh1 expressing progenitors which still persist in the zebrafish cerebellum (Kani et al., 2010), likely due to ongoing hindbrain neurogenesis in the zebrafish (Zupanc et al., 2005; Adolf et al., 2006; Kaslin et al., 2009).

\section{CONCLUSION}

The morphogenesis of cerebellar cortex development is largely conserved between ray-finned fishes and amniotes. However, the eurydendroid cells, which represent the amniote deep cerebellar nuclei, are special because they are positioned within the Purkinje cell layer in adult ray-finned fishes and are not deep to the cerebellar cortex. Thus, the migratory behavior of eurydendroid cells appears to be evolutionarily truncated. Furthermore, the molecular regulation partially differs between these vertebrate groups (number of atoh1 genes, origin of deep nuclear cells). The data reviewed and presented here speak for the presence of an EGL in early larval zebrafish, although it seems not ubiquitously present over the entire pial cerebellar surface as in amniotes. Furthermore, evidence for the existence of a simple EGL during cerebellar development has been provided for amphibians (Urey et al., 1987) and cartilaginous fishes (Rodríguez-Moldes et al., 2008). In contrast, a functional cerebellum is absent in jawless lampreys and hagfishes (Lannoo and Hawkes, 1997). Thus, since a lower and upper rhombic lip and ventral cerebellar proliferation with their major derivatives (deep cerebellar nuclei, external/internal granular layer, inhibitory cerebellar cells, precerebellar nuclei, cholinergic tegmental nuclei) occur both in anamniotes and amniotes, they likely are shared characters of gnathostomes. The situation in jawless fishes regarding the presence of a rhombic lip and the nature of its derivatives awaits future research.

\section{ACKNOWLEDGMENTS}

We thank Bea Stiening for preparing the in situ hybridized and immunohistological sections (unless otherwise stated) shown in the present paper and Enrico Kühn for various technical support. Furthermore, we thank Alena Shkumatava, Sabine Fischer, Ferenc Müller, Uwe Strähle, and Carl J. Neumann for sharing their shh-GFP line. The Munich Graduate School of Systemic Neurosciences (GSN) and the Deutsche Forschungsgemeinschaft (DFG, project $\mathrm{Wu}$ 211/2-1; Mario F. Wullimann), the Studienstiftung des deutschen Volkes (Martin Distel) and the Ministry of Education and Research (BMBF, BioFuture 0311889), and the Helmholtz Association (Reinhard W. Köster) are gratefully acknowledged for support.

adult neurogenesis in the zebrafish telencephalon. Dev. Biol. 295, 278-293.

Akazawa, C., Ishibashi, M., Shimizu, C. Nakanishi, S., and Kageyama, R. (1995). A mammalian helix-loop-helix factor structurally related to the product of Drosophila proneural gene atonall is a positive transcriptional regulator expressed in the developing nervous system. J. Biol. Chem. 270, 8730-8738.

Alder, J., Cho, N. K., and Hatten, M. E. (1996). Embryonic precursor cells from the rhombic lip are specified to a cerebellar granule neuron identity. Neuron 17, 389-399. 
Altman, J., and Bayer, S. A. (1985). Embryonic development of the rat cerebellum. I. Delineation of the cerebellar primordium and early cell movements. J. Comp. Neurol. 231, $1-26$.

Altman, J., and Bayer, S. A. (1987a). Development of the precerebellar nuclei in the rat: I: the precerebellar neuroepithelium of the rhombencephalon. J. Comp. Neurol. 257, 477-489.

Altman, J., and Bayer, S. A. (1987b). Development of the precerebellar nuclei in the rat: II: The intramural olivary migratory stream and the neurogenetic organization of the inferior olive. J. Comp. Neurol. 257, 490-512.

Altman, J., and Bayer, S. A. (1987c). Development of the precerebellar nuclei in the rat: III: the posterior precerebellar extramural migratory stream and the lateral reticular and external cuneate nuclei. J. Comp. Neurol. 257, 513-528.

Altman, J., and Bayer, S. A. (1987d). Development of the precerebellar nuclei in the rat: IV: The anterior precerebellar extramural migratory stream and the nucleus reticularis tegmenti pontis and the basal pontine gray. J. Comp. Neurol. 257, 529-552.

Altman, J., and Bayer, S. A. (1987e). Prenatal development of the cerebellar system in the rat. I. Cytogenesis and histogenesis of the deep nuclei and the cortex of the cerebellum. $J$. Comp. Neurol. 179, 23-48.

Aroca, P., Lorente-Cánovas, B., Mateos, F. R., and Puelles, L. (2006). Locus coeruleus neurons originate in alar rhombomere 1 and migrate into the basal plate: studies in chick and mouse embryos. J. Comp. Neurol. 496, 802-818.

Bae, Y. K., Kani, S., Shimizu, T., Tanabe, K., Nojima, H., Kimura, Y., Higashijima, S., and Hibi, M. (2009). Anatomy of zebrafish cerebellum and screen for mutations affecting its development Dev. Biol. 330, 406-426.

Ben-Arie, N., Bellen, H. J., Armstrong, D. L., McCall, A.E., Gordadze, P. R., Guo, Q., Matzuk, M. M., and Zoghbi, H. Y. (1997). Math1 is essential for genesis of cerebellar granule neurons. Nature 390, 169-172.

Ben-Arie, N., Hassan, B. A., Bermingham, N. A., Malicki, D. M., Armstrong, Matzuk, M. M., Bellen, H. J., and Zoghbi, H. Y. (2000). Functional conservation of atonal and Mathl in the CNS and PNS. Development 127, 1039-1048.

Berrebi,A. S., Morgan, J. I., and Mugnaini, E. (1990). The Purkinje cell class may extend beyond the cerebellum. $J$. Neurocytol. 19, 643-654.
Bloch-Gallego, E., Ezan, F., TessierLavigne, M., and Sotelo, C. (1999). Floor plate and Netrin-1 are involved in the migration and survival of inferior olivary neurons. J. Neurosci. 19, 4407-4420.

Book, K. J., and Morest, D. K. (1990). Migration of neuroblasts by perikaryal translocation: role of cellular elongation and axonal outgrowth in the acoustic nuclei of the chick embryo medulla. J. Comp. Neurol. 297, 55-76.

Bourrat, F., and Sotelo, C. (1988). Migratory pathways and neuritic differentiation of inferior olivary neurons in the rat embryo. Axonal tracing study using the in vitro slab technique. Dev. Brain Res. 39, 19-37.

Bourrat, F., and Sotelo, C. (1990). Migratory pathways and selective aggregation of the lateral reticular neurons in the rat embryo: A horseradish peroxidase in vitro study, with special reference to migration patterns of the precerebellar nuclei. J. Comp. Neurol. 294, 1-13.

Branda, C. S., and Dymecki, S. M. (2004). Talking about a revolution: the impact of site-specific recombinases on genetic analyses in mice. Dev. Cell 6, 7-28.

Cambronero, F., and Puelles, L. (2000). Rostrocaudal nuclear relationships in the avian medulla oblongata: a fate map with quail chick chimeras. J. Comp. Neurol. 427, 522-545.

Chaplin, N., Tendeng, C., and Wingate, R. J. T. (2010). Absence of an external granular layer in zebrafish and shark reveals a distinct, amniote ground plan of cerebellum development. J. Neurosci. 30, 3048-3057.

Chédotal, A. (2010). Should I stay or should I go? Becoming a granule cell. Trends Neurosci. 33, 163-172.

Chédotal, A., Bloch-Gallego, E., and Sotelo, C. (1997). The embryonic cerebellum contains topograhic cues that guide developing inferior olivary axons. Development 124, 861-870.

Clack, J.A. (1997). The evolution of tetrapod ears and the fossil record. Brain Behav. Evol. 50, 198-212.

Clemente, D., Porteros, A., Weruaga, E., Alonso, J. R., Arenzana, F. J., Aijon, J., and Arevalo, R. (2004). Cholinergic elements in the zebrafish central nervous system: histochemical and immunohistochemical analysis. J. Comp. Neurol. 474, 75-107.

Curran, T., and D'Arcangelo, G. (1998). Role of reelin in the control of brain development. Brain Res. Rev. 26, 285-294.

D'Arcangelo, G., and Curran, D. (1998). Reeler: new tales on an old mutnat mouse. Bioessays 20, 235-244.

Distel, M., Babaryka, A., and Köster, R. W. (2006). Multicolor in vivo timelapse imaging at cellular resolution by stereomicroscopy. Dev. Dyn. 235, 843-845.

Distel, M., Hocking, J. C., Volkmann, K., and Köster, R. W. (2010). The centrosome neither persistently leads migration nor determines the site of axonogenesis in migrating neurons in vivo. J. Cell Biol. 15, 875-890.

Distel, M., Wullimann, M. F., and Köster, R.W. (2009). Optimized Gal4 genetics for permanent gene expression mapping in zebrafish. Proc. Natl. Acad. Sci. U.S.A. 106, 13365-13370.

Dubbeldam, J. L. (1998). "Birds," in The Central Nervous System of Vertebrates, eds R. Nieuwenhuys, H. J. Ten Donkelaar, C. Nicholson (Berlin: Springer), 1525-1636.

Echelard, Y., Vassileva, G., and McMahon, A. P. (1994). Cis-acting regulatory sequences governing Wnt-1 expression in the developing mouse CNS Development 120, 2213-2224.

Elsen, G. E., Choi, L. Y., Millen, K. J., Grinblat, Y., and Prince, V. E. (2008). Zic1 and Zic4 regulate zebrafish roof plate specification and hindbrain ventricle morphogenesis. Dev. Biol. 314, 376-392.

Engelkamp, D., Rashbase, P., Seawright, A., and van Heyningen, V. (1999). Role of Pax6 in development of the cerebellar system. Development 126 3585-3596.

Englund, C., Kowalcyk, T., Daza, R. A. M., Dagan, A., Lau, C., Rose, M. F., and Hevner, R. F. (2006). Unipolar brush cells of the cerebellum are produced in the rhombic lip and migrate through developing white matter. J. Neurosci. 26, 9184-9195.

Farago, A. F., Awatramani, R. B., and Dymecki, S. M. (2006). Assembly of the brainstem cochlear nuclear complex is revealed by intersectional and subtractive genetic fate maps. Neuron 50, 205-218.

Fink, A. J., Englund, C., Daza, R. A. M., Pham, D., Lau, C., Nivison, M. Kowalcyk, T., and Hevner, R. F. (2006) Development of the deep cerebellar nuclei: transcription factors and cell migration from the rhombic lip. $J$. Neurosci. 26, 3066-3076.

Fujiyama, T., Yamada, M., Terao, M. Terashima, T., Hioki, H., Inoue, Y. U., Inoue, T., Masuyama, N., Obata, K., Yanawaga, Y., Kawaguchi,Y., Nabeshima, Y., and Hoshino, M. (2009). Inhibitory and excitatory subtypes of cochlear nucleus neurons are defined by distinct bHLH transcription factors, Ptfla and Atoh1. Development 136, 2049-2058.

Fujta, S. (1967). Quantitative analysis of cell proliferation and differentiation in the cortex of the postnatal mouse cerebellum. J. Cell Biol. 32, 277-287.

Gilthorpe, J. D., Papantoniou, E.-K., Chédotal, A., Lumsden, A., and
Wingate, R.J.T. (2002). The migration of cerebellar rhombic lip derivatives. Development 129, 4719-4728.

Goldowitz, D., and Hamre, K. (1998). The cells and molecules that make a cerebellu. Trends Neurosci. 21, 375-382.

Grothe, B. (2003). New roles for synaptic inhibition in sound localization. Nat. Rev. Neurosci. 4, 1-11.

Grothe, B., Carr, C. E., Casseday, J. H., Fritzsch, B., and Köppl, C. (2004). "The evolution of central pathways and their neural processing patterns," in Evolution of the Vertebrate Auditory System. Springer Handbook of Auditory Research, eds G. A. Manley, A. N. Popper, and R. R. Fay (Springer: New York), 289-359.

Hanaway, J. (1967). Formation and differentiation of the external granular layer of the chick cerebellum. J. Comp. Neurol. 131, 1-14.

Harkmark, W. (1954). Cell migrations from the rhombic lip to the inferior olive, the nucleus raphe and the pons. A morphological and experimental investigation on chick embryos. $J$. Comp. Neurol. 100, 115-209.

Hatten, M. E. (1990). Riding the glial monorail: a common mechanism for glial-guided neuronal migratin in different regions of the developing mammalian brain. Trends Neurosci. 13, 179-184.

Hatten, M.E. (1999). Central nervous system neuronal migration. Annu. Rev. Neurosci. 22, 511-539.

Hatten, M. E., and Heintz, N. (1995). Mechanisms of neural patterning and specification in the developing cerebellum. Annu. Rev. Neurosci. 18, 385-408.

Hatten, M.E., Alder, J., Zimmermann, K., and Heintz, N. (1997). Genes involved in cerebellar cell differentiation specification and differentiation. Curr. Opin. Neurobiol. 7, 40-47.

Hatten, M. E., and Mason, C. A. (1990). Mechanisms of glial-guided neuronal migration in vitro and in vivo. Experientia 46, 907-916.

Helms, A. W., Abney, A. L., Ben-Arie, N., Zoghbi, H. Y., and Johnson, J. E. (2000). Autoregulation and multiple enhancers control Math1 expression in the developing nervous system. Development 127, 1185-1196.

Hoshino, M. (2006). Molecular machinery governing GABAergic neuron specification in the cerebellum. Cerebellum 5, 193-198.

Hoshino, M., Nakamura, S., Mori, K., Kawauchi, T., Terao, M., Nishimura, Y. V., Fukuda, A., Fuse, T., Matsuo, N., Sone, M., Watanabe, M., Bito, H., Terashima, T., Wright, C. V., Kawaguchi, Y., Nakao, K., and Nabeshima, Y. (2005). Ptfla, a bHLH transcriptional gene, defines 
GABAergic neuronal fates in cerebellum. Neuron 47, 201-213.

Huang, X., Ketova, T., Fleming, J. T., Wang, H., Dey, S. K., Litingtung, Y., and Chiang, C. (2009). Sonic hedgehog signaling regulates a novel epithelial progenitor domain of the hindbrain choroid plexus. Development 136 , 2535-2543.

Ikenaga, T., Yoshida, M., and Uematsu, K. (2005). Morphology and immunohistochemistry of efferent neurons of the goldfish corpus cerebelli. J. Comp. Neurol. 487, 300-311.

Ito, M. (2006). Cerebellar circuitry as a neuronal machine. Prog. Neurobiol. 78, 272-303.

Ivanova, A., and Yuasa, S. (1998). Neuronal migration and differentiation in the development of the mouse dorsal cochlear nucleus. Dev. Neurosci. 20, 495-511.

Jászai, J., Reifers, F., Picker, A., Langenberg, T., and Brand, M. (2003). Isthmusto-midbrain transformation in the absence of midbain-hindbrain organizer activity. Development 130, 6611-6623.

Kani, S., Bae, Y.-Y., Shimizu, T., Tanabe, K., Satou, C., Parsons, M. J., Scott, E., Higashijima, S., and Hibi, M. (2010). Proneural gene-linked neurogenesis in zebrafish cerebellum. Dev. Biol. 343, 1-17.

Kaslin, J., Ganz, J., Geffarth, M., Grandel, H., Hans, S., and Brand, M. (2009). Stem cells in the adult zebrafish cerebellum: initiation and maintenance of a novel stem cell niche. J. Neurosci. 29, 6142-6153.

Kim, C. H., Bae, Y. K., Yamanaka, Y., Yamashita, S., Shimizu, T., Fujii, R., Park, H. C., Yeo, S. Y., Huh, T. L., Hibi, M., and Hirano, T. (1997). Overexpression of neurogenin induces ectopic expression of $\mathrm{HuC}$ in zebrafish. Neurosci. Lett. 239, 113-116.

Kim, E. J., Battiste, J., Nakagawa, Y., and Johnson, J. E. (2008). Ascll (Mash1) lineage cells contribute to discrete cell populations in CNS architecture. Mol. Cell. Neurosci. 38, 595-606.

Komuro, H., and Rakic, P. (1998a). Distinct modes of neuronal migration in different domains of developing cerebellar cortex. J. Neurosci. 18, 1478-1490.

Komuro, H., and Rakic, P. (1998b). Orchestration of neuronal migration by activity of ion channels, neurotransmitter receptors, and intracellular $\mathrm{Ca}^{2+}$ fluctuations. J. Neurobiol. 37, 110-130.

Köster, R. W., and Fraser, S. E. (2001a). Direct imaging of in vivo neuronal migration in the developing cerebellum. Curr. Biol. 11, 1858-1863.

Köster, R. W., and Fraser, S. E. (2001b). Tracing transgene expression in living zebrafish embryos. Dev. Biol. 233, 329-346.

Köster, R. W., and Fraser, S. E. (2006). FGF signaling mediates regeneration of the differentiating cerebellum through repatterning of the anterior hindbrain and reinitiation of neuronal migration. J. Neurosci. 26, 7293-7304.

Kriegstein, A., and Alvarez-Buylla, A. (2009). The glial nature of embryonic and adult neural stem cells. Annu. Rev. Neurosci. 32, 149-184.

Landsberg, R. L., Awatrami, R. B., Hunter, N. L., Farago, A., DiPietrantonio, H. J., Rodriguez, C. I., and Dymecki, S. M. (2005). Hindbrain rhombic lip is comprised of discrete progenitor cell populations allocated by Pax6. Neuron 48, 933-947.

Lannoo, M. J., and Hawkes, R. (1997). A search for primitive Purkinje cells: zebrin II expression in sea lampreys (Petromyzon marinus). Neurosci. Lett. 237, 53-55.

Lannoo, M. J., Ross, L., Maler, L., and Hawkes, R. (1991). Development of the cerebellum and ist extracerebellar Purkinje cell projection in teleost fishes as determined by Zebrin-II immunocytochemistry. Prog. Neurobiol. 37, 329-363.

Lekven, A. C., Buckles, G. R., Kostakis, N., and Moon, R. T. (2003). wntl and wnt $10 \mathrm{~b}$ function redundantly at the zebrafish midbrain-hindbrain boundary. Dev. Biol. 254.172-187.

Leto, K., Calretti, B., Williams, I. M., Magrassi, L., and Rossi, F. (2006). Different types of cerebellar GABAergic interneurons originate from a common pool of multipotent progenitor cells. J. Neurosci. 26, 11682-11694.

Lin, J. C., Cai, L., and Cepko, C. L. (2001). The external granular layer of the developing chick cerebellum generates granule cells and cells of the isthmus and rostral hindbrain. J. Neurosci. 21, 159-168.

Liu, A., and Joyner, A. (2001). Early anterior/posterior patterning of the midbrain hindbrain and cerebellum. Annu. Rev. Neurosci. 24, 869-896.

Liu, Z., Li, H., Hu, X., Yu, L., Liu, H., Han, R., Colella, R., Mower, G. D., Chen, Y., and Qiu, M. (2008). Control of precerebellar neuron development by Olig3 bHLH transcription factor. J. Neurosci. 28, 10124-10133.

Lundell, T. G., Zhou, Q., and Doughty, M. L. (2009). Neurogenin 1 expression in cell lineages of the cerebellar cortex in embryonic and postnatal mice. Dev. Dyn. 238, 3310-3325.

Machold, R., and Fishell, G. (2005). Math1 is expressed in temporally discrete pools of cerebellar rhombic-lip neural progenitors. Neuron 48, 17-24.
Machold, R. P., Jones-Kittel, D., and Fishell, G. J. (2007). Antagonism between Notch and bone morphogenetic protein receptor signaling regulates neurogenesis in the cerebellar rhombic lip. Neural Dev. 2, 1-13.

Marín, F., and Puelles, L. (1995). Morphological fate of rhombomeres in quail/chick chimeras: a segmental analysis of hindbrain nuclei. Eur. J. Neurosci. 7, 1714-1738.

Martí, E., and Bovolenta, P. (2002). Sonic hedgehog in CNS development: one signal, multiple outputs. Trends Neurosci. 25, 89-96.

Marusich, M. F., Furneaux, H. M., Henion, P.D., and Weston, J.A. (1994). Hu neuronal proteins are expressed in proliferating neurogenic cells. J. Neurobiol. 25,143-155.

McCormick, C. A., and Braford, M. R. Jr. (1994). Organization of inner ear endorgan projections in the goldfish, Carassius auratus. Brain Behav. Evol. 43, 189-205.

McCormick, C. A., and Hernandez, D. V. (1996). Connections of the octaval and lateral line nuclei of the medulla in the goldfish, including the cytoarchitecture of the secondary octaval population in goldfish and catfish. Brain Behav. Evol. 47, 113-138.

McFarland, K. A., Topczewska, J. M., Weidinger, G., Dorsky, R. I., and Appel, B. (2008). Hh and Wnt signaling regulate formation of olig2+ neurons in the zebrafish cerebellum. Dev. Biol. 318 , 162-171.

Miale, I. L., and Sidman, R. L. (1961) An autoradiographic analysis of histogenesis in the mouse cerebellum. Exp. Neurol. 4, 277-296.

Mikami, Y., Yoshida, T., Matsuda, N., and Mishina, M. (2004). Expression of zebrafish glutamate receptor ( 2 in neurons with cerebellum-like wiring. Biochem. Biophys. Res. Commun. 322, 168-176.

Miyamura, Y., and Nakayasu, H. (2001) Zonal distribution of Purkinje cells in the zebrafish cerebellum: analysis by means of a specific monoclonal antibody. Cell Tissue Res. 305, 299-305.

Miyata, T., Maeda, T., and Lee, J. E. (1999). NeuroD is required for differentiation of the granule cells in the cerebellum and hippocampus. Genes Dev. 13 1647-1652.

Mueller, T., Vernier, P., and Wullimann, M. F. (2004). The adult central nervous cholinergic system of a neurogenetic model animal, the zebrafish Danio rerio. Brain Res. 1011,156-169.

Mueller, T., Vernier, P., and Wullimann, M. F. (2006). A phylotypic stage in vertebrate brain development: GABA cell patterns in zebrafish compared with mouse. J. Comp. Neurol. 494, 620-634.
Mueller, T., and Wullimann, M. F. (2002). BrdU-, neuroD-(nrd) and Hu-studies show unusual non-ventricular neurogenesis in the postembryonic zebrafish forebrain. Mech. Dev. 117:, 123-135.

Mueller, T., and Wullimann, M. F. (2003). Anatomy of neurogenesis in the zebrafish brain. Dev. Brain Res. 140, 135-153.

Mueller, T., and Wullimann, M. F. (2005). Atlas of Early Zebrafish Brain Development: A Tool for Molecular Neurogenetics. Amsterdam: Elsevier.

New, J. G., Coombs, S., McCormick, C. A., and Oshel, P. E. (1996). Cytoarchitecture of the medial octavolateralis nucleus in the goldfish, Carassius auratus. J. Comp. Neurol. 366, 534-546.

Nichols, D. H., and Bruce, L. L. (2006). Migratory routes and fates of cells transcribing the Wnt-1 gene in the murine hindbrain. Dev. Dyn. 235, 285-300.

Nielsen, C. M., and Dymecki, S. M. (2010). Sonic hedgehog is required for vascular outgrowth in the hindbrain choroid plexus. Dev. Biol. 340, 430-437.

Nieuwenhuys, R. (1998). "Histogenesis," in The Central Nervous System of Vertebrates, eds R. Nieuwenhuys, H. J. Ten Donkelaar, and C. Nicholson (Berlin: Springer), 229-271.

Ono, K., and Kawamura, K. (1989). Migration of immature neurons along tangentially oriented fibers in the subpial part of the fetal mouse medulla oblongata. Exp. Brain Res. 78, 290-300.

Ono, K., and Kawamura, K. (1990). Mode of neuronal migration of the pontine stream in fetal mice. Anat. Embryol. 182, 11-19.

Ono, K., Yasui, Y., and Ikenaka, K. (2004). Lower rhombic lip-derived cells undergo transmedian tangential migration followed by radial migration in the chick embryo brainstem. Eur. J. Neurosci. 20, 914-922.

Osório, J., Mueller, T., Rétaux, S., Vernier, P., and Wullimann, M. F. (2010). Phylotypic expression of the bHLH genes Neurogenin2, NeuroD, and Mash1 in the mouse embryonic forebrain. J. Comp. Neurol. 518, 851-871.

Rakic, P. (1990). Principles of neural cell migration. Experientia 46, 882-891.

Ray, R. S., and Dymecki, S. M. (2009). Rautenlippe Redux - toward a unified view of the precerebellar rhombic lip. Curr. Opin. Cell Biol. 21, 741-747.

Redzic, Z. B., Preston, J. E., Duncan, J. A., Chodobski, A., and SzmydyngerChodobska, J. (2005). The choroid plexus-cerebrospinal fluid system: from development to aging. Curr. Top. Dev. Biol. 71, 1-52. 
Rieger, S., Volkmann, K., and Köster, R.W. (2008). Polysialyltransferase expression is linked to neuronal migration in the developing and adult zebrafish. Dev. Dyn. 237, 276-285.

Rodriguez, C. I., and Dymecki, S. M. (2000). Origin of thel precerebellar system. Neuron 27, 475-486.

Rodríguez-Moldes, I., Ferreiro-Galve, S., Carrera, I., Sueiro, C., Candal, E., Mazan, S., and Anadón, R. (2008). Development of the cerebellar body in sharks: spatiotemporal Pax6 expression, cell proliferation and differentiation. Neurosci. Lett. 432, 105-110.

Rose, M. F., Ahmad, K. A., Thaller, C., and Zoghbi, H. Y. (2009). Excitatory neurons of the proprioceptive, interoceptive, and arousal hindbrain networks share a developmental requirement for Math1.Proc. Natl. Acad. Sci. U.S.A. 106, 22462-22467.

Ryder, E. F., and Cepko, C. L. (1994). Migration patterns of clonally related granule cells and their progenitors in the developing chick cerebellum. Neuron 12, 1011-1029.

Saul, S. M., Brzezinski, J. A. IV, Altschuler, R. A., Shore, S. E., Rudolph, D. D., Kabara, L. L., Halsey, K. E., Hufnagel, R. B., Zhou, J., Dolan, D. F., and Glaser, T. (2008). Math5 expression and function in the central auditory system. Mol. Cell. Neurosci. 37, 153-169.

Sgaier, K. S., Millet, S., Villaneuva, M. P., Berenshteyn, F., Song, C., and Joyiner, A. L. (2005). Morphogenetic and cellular movements that shape the mouse cerebellum: insights form genetic fate mapping. Neuron 45 , 27-40.

Sillitoe, R. V., and Joyner, A. L. (2007). Morphology, molecular codes, and circuitry produce the three-dimensional complexity of the cerebellum. Annu. Rev. Cell Dev. Biol. 23, 549-577.

Shkumatava, A., Fischer, S., Müller, F., Strahle, U., and Neumann, C. J. (2004). Sonic hedgehog, secreted by amacrine cells, acts as a short-range signal to direct differentiation and lamination in the zebrafish retina. Development 131, 3849-3858.

Sotelo, C. (2004). Cellular and genetic regulation of the development of the cerebellar system. Prog. Neurobiol. 72, 295-339.

Storm, R., Cholewa-Waclaw, J., Reuter, K., Bröhl, D., Sieber, M., Treier, M., Müller, T., and Birchmeier, C. (2009). The bHLH trancsription factor Olig3 marks the dorsal neuroepithelium of the hindbrain and is essential for the development of brainstem nuclei. Development 136, 295-305.

Taber-Pierce, E. (1966). Histogenesis of the nuclei griseum pontis, corporis pontobulbaris and reticularis tegmenti pontis (Bechterew) in the mouse. an autoradiographic study. J. Comp. Neurol. 126, 219-240.

Taber-Pierce, E. (1967). Histogenesis of the dorsal and ventral cochlear nuclei in the mouse. An autoradiographic study. J. Comp. Neurol. 131, 27-54.

Taber-Pierce, E. (1975). Histogenesis of the deep cerebellar nuclei in the mouse: an autoradiographic study. Brain Res. 95, 503-518.

Tan, K., and LeDouarin, N. M. (1991). Development of the nuclei and cell migration in the medulla oblongata. Application of the quail-chick chimera system. Anat. Embryol. 183, 321-343.

Traiffort, E., Charytoniuk, D., Watroba, L., Faure, H., Sales, N., and Ruat, M. (1999). Discrete localizations of hedgehog signalling components in the developing and adult rat nervous system. Eur. J. Neurosci. 11,3199-3214.

Traiffort, E., Charytoniuk, D. A., Faure, H., and Ruat, M. (1998). Regional distribution of sonic hedgehog, patched, and smoothened mRNA in the adult rat brain. J. Neurochem. 70, 1327-1330.

Urey, N. J., Gona, A. G., and Hauser, K. F. (1987). Autoradiographic studies of cerebellar histogenesis in the prematomorphic bullfrog tadpole: I. Generation of the external granular layer. J. Comp. Neurol. 266, 234-246.

Volkmann, K., Chen, Y.-Y., Harris, M. P., Wullimann, M. F., and Köster, R. W. (2010). The zebrafish cerebellar upper rhombic lip generates tegmental hindbrain nuclei by long - distance migration in an evolutionary conserved manner. J. Comp. Neurol. 518, 2794-2817.

Volkmann, K., Rieger, S., Babaryka, A., and Köster, R. W. (2008). The zebrafish cerebellar rhombic lip is spatially patterned in producing granule cell populations of different functional compartments. Dev. Biol. 313, 167-180.

Voogd, J., and Glickstein, M. (1998). The anatomy of the cerebellum. Trends Neurosci. 21, 370-375.

Wang, V. Y., Rose, M. F., and Zoghbi, H. Y. (2005). Math1 expression redefines the rhombic lip derivatives and reveals novel lineages within the brainstem and cerebellum. Neuron 48, 31-43.

Wang, V. Y., and Zoghbi, J. Y. (2001) Genetic regulation of cerebellar development. Nat. Rev. Neurosci. 2 , 484-491.

Wang, Y., Chen, K., Yao, Q., Zhengh, X., and Yang, Z. (2009). Phylogenetic analysis of zebrafish basic helix-loophelix transcription factors. J. Mol. Evol. 68, 629-640.

Weisheit, G., Gliem, M., Endl, E., Pfeffer, P. L., Busslinger, M., and Schilling, K. (2006). Postnatal development of the murine cerebellar cortex: formation and early dispersal of basket, stellate and Golgi neurons. Eur. J. Neurosci. 24, 466-478.

Willard, F. H., and Martin, G. F. (1986). The development and migration of large multipolar neurons into the cochlear nucleus of the North American opossum. J. Comp. Neurol. 248, 119-132.

Wilson, L. J., and Wingate, R. J. T. (2006) Temporal identity transition in the avian cerebellar rhombic lip. Dev. Biol. 297, 508-521.

Wingate, R. J. T. (2001). The rhombic lip and early cerebellar development. Curr. Opin. Neurobiol. 11, 82-88.

Wingate, R. J. T., and Hatten, M. E. (1999). The role of the rhombic lip in avian cerebellum development. Development 126, 4395-4404.

Wullimann, M. F., and Mueller, T. (2002). Expression of Zash-1a in the postembryonic zebrafish brain allows comparison to mouse Mash1 domains. Gene Expr. Patterns 1, 187-192.

Wullimann, M. F., and Northcutt, R. G. (1988). Connections of the corpus cerebelli in the green sunfish and the common goldfish: a comparison of perciform and cypriniform teleosts. Brain Behav. Evol. 32, 293-316.

Wullimann, M. F., and Rink, E. (2001) Detailed immunohistology of Pax6 protein and tyrosine hydroxylase in the early zebrafish brain suggests role of Pax6 gene in development of dopaminergic diencephalic neurons. Dev. Brain Res. 131, 173-191.

Wullimann, M. F., and Vernier, P. (2007). "Evolution of the nervous system in fishes," in Evolution of Nervous Systems 3: Evolution of Nervous Systems in NonMammalian Vertebrates, ed. J. Kaas (Amsterdam: Elsevier), 39-60.
Wurst, W., and Bally-Cuif, L. (2001). Neural plate patterning: upstream and downstream ofl the isthmic organizer. Nat. Rev. Neurosci. 2, 99-108.

$\mathrm{Xu}, \mathrm{H}$. G., Yang, C.-Y., and Yamamoto, N. (2008). Afferent sources to the inferior olive an distribution of the olivocerebellar climbing fibers in cyprinids. J. Comp. Neurol. 507, 1409-1427.

Yamada, M., Terao, M., Terashima, T., Fujiyama, T., Kawaguchi, Y., Nabeshima, Y., and Hoshino, M. (2007). Origin of climbing fiber neurons and their developmental dependence on Ptfla. J. Neurosci. 27, 10924-10934.

Zhang, L., and Goldman, J. E. (1996). Developmental fates and migratory pathways of dividing progenitors in the postnatal rat cerebellum. J. Comp. Neurol. 370, 536-550.

Zordan, P., Croci, L., Hawkes, R., and Consalez, G. G. (2008). Comparative analysis of proneural gene expression in the embryonic cerebellum. Dev. Dyn. 237, 1726-1735.

Zupanc, G. K., Hinsch, K., and Gage, F. H. (2005). Proliferation, migration, neuronal differentiation, and longterm survival of new cells in the adult zebrafish brain. J. Comp. Neurol. 488, 290-319.

Conflict of Interest Statement: The authors declare that the research was conducted in the absence of any commercial or financial relationships that could be construed as a potential conflict of interest.

Received: 07 December 2010; paper pending published: 11 January 2011; accepted: 06 April 2011; published online: 21 April 2011.

Citation: Wullimann MF, Mueller T, Distel M, Babaryka A, Grothe B and Köster RW (2011) The long adventurous journey of rhombic lip cells in jawed vertebrates: a comparative developmental analysis. Front. Neuroanat. 5:27. doi: 10.3389/ fnana.2011.00027

Copyright (C) 2011 Wullimann, Mueller, Distel, Babaryka, Grothe and Köster. This is an open-access article subject to a nonexclusive license between the authors and Frontiers Media SA, which permits use, distribution and reproduction in other forums, provided the original authors and source are credited and other Frontiers conditions are complied with. 